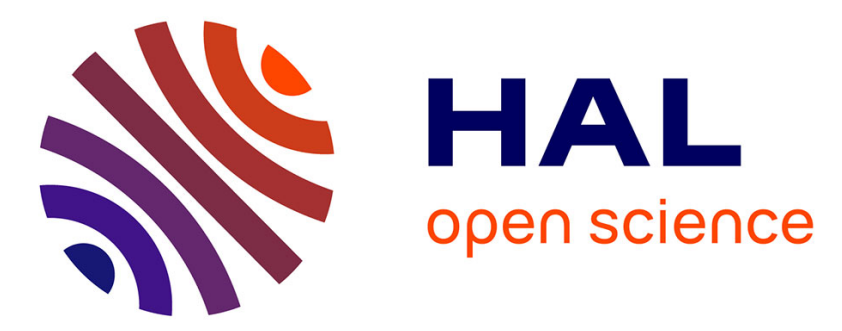

\title{
Relationships between synthesis and mechanical properties of new polyurea materials
}

\author{
Nathalie Samson, Françoise Méchin, Jean-Pierre Pascault
}

\section{To cite this version:}

Nathalie Samson, Françoise Méchin, Jean-Pierre Pascault. Relationships between synthesis and mechanical properties of new polyurea materials. Journal of Applied Polymer Science, 1997, 65 (12), pp.2265-2280. 10.1002/(SICI)1097-4628(19970919)65:123.0.CO;2-7 . hal-02045935

\section{HAL Id: hal-02045935 \\ https://hal.science/hal-02045935}

Submitted on 20 Nov 2020

HAL is a multi-disciplinary open access archive for the deposit and dissemination of scientific research documents, whether they are published or not. The documents may come from teaching and research institutions in France or abroad, or from public or private research centers.
L'archive ouverte pluridisciplinaire HAL, est destinée au dépôt et à la diffusion de documents scientifiques de niveau recherche, publiés ou non, émanant des établissements d'enseignement et de recherche français ou étrangers, des laboratoires publics ou privés. 


\title{
Relationships Between Synthesis and Mechanical Properties of New Polyurea Materials
}

\author{
NATHALIE SAMSON, FRANÇOISE MÉCHIN, JEAN-PIERRE PASCAULT \\ Laboratoire des Matériaux Macromoléculaires, UMR CNRS No. 5627, \\ Institut National des Sciences Appliquées de Lyon, \\ Bât. 403, 20 avenue Albert Einstein, 69621 Villeurbanne Cedex, France
}

\begin{abstract}
New segmented polyureas were prepared from 4,4'-diisocyanato dicyclohexylmethane and amino terminated polyoxypropylene. Different cycloaliphatic and aromatic diamines were used as chain extenders as well as to synthesize the corresponding model hard segments (HSs). The competition between polycondensation and HS crystallization requires a sufficiently fast reaction (e.g., cycloaliphatic diamines associated with a catalyst, if necessary in solution), although low reactivity monomers would be necessary to avoid demanding processing techniques such as reaction injection molding; otherwise, materials with isolated (i.e., not chemically linked) HS are obtained and they display poor mechanical properties. In contrast, when an appropriate synthesis procedure is used, elastomers with high molar masses and narrow molar mass distributions can be obtained. These characteristics, associated with the high melting temperature of the hard domains, result in very good mechanical behavior, up to high enough temperatures $\left(\sim 180-190^{\circ} \mathrm{C}\right)$. The presence of low molar masses can be responsible for a rather low but continuous energy dissipation between the relaxations of the soft and hard domains (and particularly at room temperature), but can be well limited by a short thermal treatment at high temperature
\end{abstract}

Key words: polyurea; diamines; mechanical properties; competition between kinetics and crystallization/phase separation

Published in Journal of Applied Polymer Science vol. 65, 2265-2280, 1997 


\section{INTRODUCTION}

Thermoplastic segmented polyurea elastomers are block copolymers of the $(A B)_{n}$ type, consisting of alternating soft and hard segments. Generally, the bulk synthesis of segmented polyureas is carried out by reacting a mixture of aliphatic and aromatic diamines with aromatic isocyanates by reaction injection molding (RIM), because the rates of reaction are such that RIM is the only suitable process to form these engineering polymers. ${ }^{1-7}$ Small angle X-ray scattering (SAXS), differential scanning calorimetry (DSC), and dynamic mechanical analysis showed that microphase separation between the soft and hard segments occurred by spinodal decomposition during the reaction and gave materials with a non-equilibrium morphology., ${ }^{3,4}$ Compared to classical polyurethanes, the use of an amine terminated instead of alcohol terminated chain extender and soft segment led to the introduction of urea linkages, which enhanced interaction through hydrogen bonds and preserved properties up to a higher temperature.

The first aim of this study was to synthesize and characterize novel segmented polyureas that, as far as possible, might be processed by casting. The synthesis of pure hard segments and segmented polyureas and their physicochemical characterization are described. A judicious choice of specific low reactivity monomers should allow the formation of pure hard segments as well as segmented polyureas by bulk polycondensation at atmospheric pressure. For more reactive diamine chain extenders, solution polycondensation methods were also investigated. The synthesis of segmented polyurethane ureas in solution was recently studied ${ }^{8-13}$ but the solution preparation of segmented polyureas seemed to be little investigated. ${ }^{7,14}$ However, it can be inferred that a careful selection of solvent and reactant concentration and a good control of the reaction temperature are essential to obtain optimal results.

Our final purpose was to investigate the effect of the nature of the diamine chain extender and of the hard segment content on the morphology and properties of these materials. A lot of work has been done on the mechanical behavior of RIM polyureas ${ }^{2-6,10,15-20}$ and polyurethane ureas. ${ }^{21,22}$ Their elastomeric behavior results from interactions between coexisting hard and soft phases that are formed by block immiscibility. The present work illustrates the importance of a good control of the involved chemistry and thermal history on the final properties of the materials.

\section{EXPERIMENTAL}

\section{Materials}

All reactant structures are shown in Table I. Desmodur W (Bayer) is a cycloaliphatic diisocyanate composed of a mixture of the three isomers (trans, trans, cis, trans, and cis, cis) of 4,4'diisocyanatodicyclohexylmethane or $\mathrm{H}_{12} \mathrm{MDI}$ and was used without further purification. It is a low viscosity liquid with an isocyanate equivalent mass of $131 \mathrm{~g} / \mathrm{mol}$ (determined by isocyanate titration using the ASTM D1638-74 method).

Jeffamine D-2000 (Huntsman) is a polyoxypropylene diamine with a molar mass of $2060 \mathrm{~g} / \mathrm{mol}$ and a functionality slightly less than $2.0(\sim 1.96)$. Before any polymer synthesis, Jeffamine was degassed under a vacuum at $60^{\circ} \mathrm{C}$ for $12 \mathrm{~h}$ to remove any absorbed moisture.

The aromatic diamine chain extenders used here were either di(methylthio) toluene diamine (Ethacure 300/Ethyl) or 4,4'-methylenebis(2,6-diethylaniline) (MDEA/Lonza). 
Three cycloaliphatic diamines were chosen: 4,4'-methylenebis(cyclohexyl amine) (PACM/Aldrich), 4,4'methylenebis(2-methyl cyclohexylamine) (3-DCM or Laromin C260/BASF), and 4,4'-methylenebis(2methyl 6-ethyl cyclohexylamine) (M-MECHA/Lonza). PACM is semicrystalline (it is a mixture of different isomers); 3-DCM and M-MECHA are amorphous and liquid at room temperature.

$\mathrm{N}, \mathrm{N}$-Dimethylformamide (DMF; boiling point temperature, $T_{\mathrm{bp}}=150^{\circ} \mathrm{C}$ ), $\mathrm{N}, \mathrm{N}$-dimethylacetamide $\left(\right.$ DMAc; $\left.T_{\text {bp }}=170^{\circ} \mathrm{C}\right)$, and 1-methyl 2-pyrrolidinone (NMP, $T_{\text {bp }}=205^{\circ} \mathrm{C}$ ) were dehydrated with $4 \AA$ type molecular sieves. Tetrahydrofuran $(\mathrm{THF},>99.7 \%)$ and anhydrous lithium chloride were quite pure, and both were used as received. Some syntheses were carried out with dibutyltin dilaurate (DBTDL/Fluka) as catalyst.

\section{Pure Hard Segment Synthesis}

Given their respective basicity and steric hindrance, the reactivity of the diamines used should be in the following range $\mathrm{e}^{23}$ :

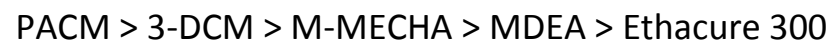

Ethacure 300 is amorphous. Its reactivity at room temperature is low, so that its homogeneous mixing with $\mathrm{H}_{12} \mathrm{MDI}$ is possible under such conditions. $\left(-\mathrm{H}_{12} \mathrm{MDI}-\text { Ethacure } 300-\right)_{n}$ hard segments (stoichiometry $\mathrm{NCO} / \mathrm{NH}_{2}=1$ ) were consequently synthesized by a bulk polycondensation method. The reaction was carried out at $80^{\circ} \mathrm{C}$ for $8 \mathrm{~h}$.

The bulk mixing of $\mathrm{H}_{12} \mathrm{MDI}$ and MDEA would need to be made above the melting temperature of MDEA $\left(T_{m}=89^{\circ} \mathrm{C}\right)$. Because of the high reactivity of MDEA with diisocyanates at such a temperature, their complete homogeneous mixing before reaction without the help of a RIM machine was impossible. Therefore, $\left(-\mathrm{H}_{12} \mathrm{MDI}-\mathrm{MDEA}-\right)_{n}$ hard segments were synthesized by solution polycondensation at $60^{\circ} \mathrm{C}$ for $24 \mathrm{~h}$. The use of different polar solvents like THF, DMF, DMAc, and NMP was studied.

3-DCM and M-MECHA are amorphous at room temperature but are much more reactive than MDEA because of their cycloaliphatic structure. PACM is solid at room temperature. Thus $\left(-\mathrm{H}_{12} \mathrm{MDI}-\right.$ PACM -$)_{n}, \quad\left(-\mathrm{H}_{12} \mathrm{MDI}-3 \mathrm{DCM}-\right)_{n}$, and $\left(-\mathrm{H}_{12} \mathrm{MDI}-\mathrm{M}-\mathrm{MECHA}-\right)_{n}$ hard segments were also synthesized by solution polycondensation in $\mathrm{DMF}$ at $80^{\circ} \mathrm{C}$. The overall reactant concentration of the solutions was $17 \mathrm{wt} \%$.

The hard segments prepared in solution were evaporated and dried in a vacuum oven at $80^{\circ} \mathrm{C}$ for 3 days. 
Table I Chemical structures and thermal characteristics of the reactants

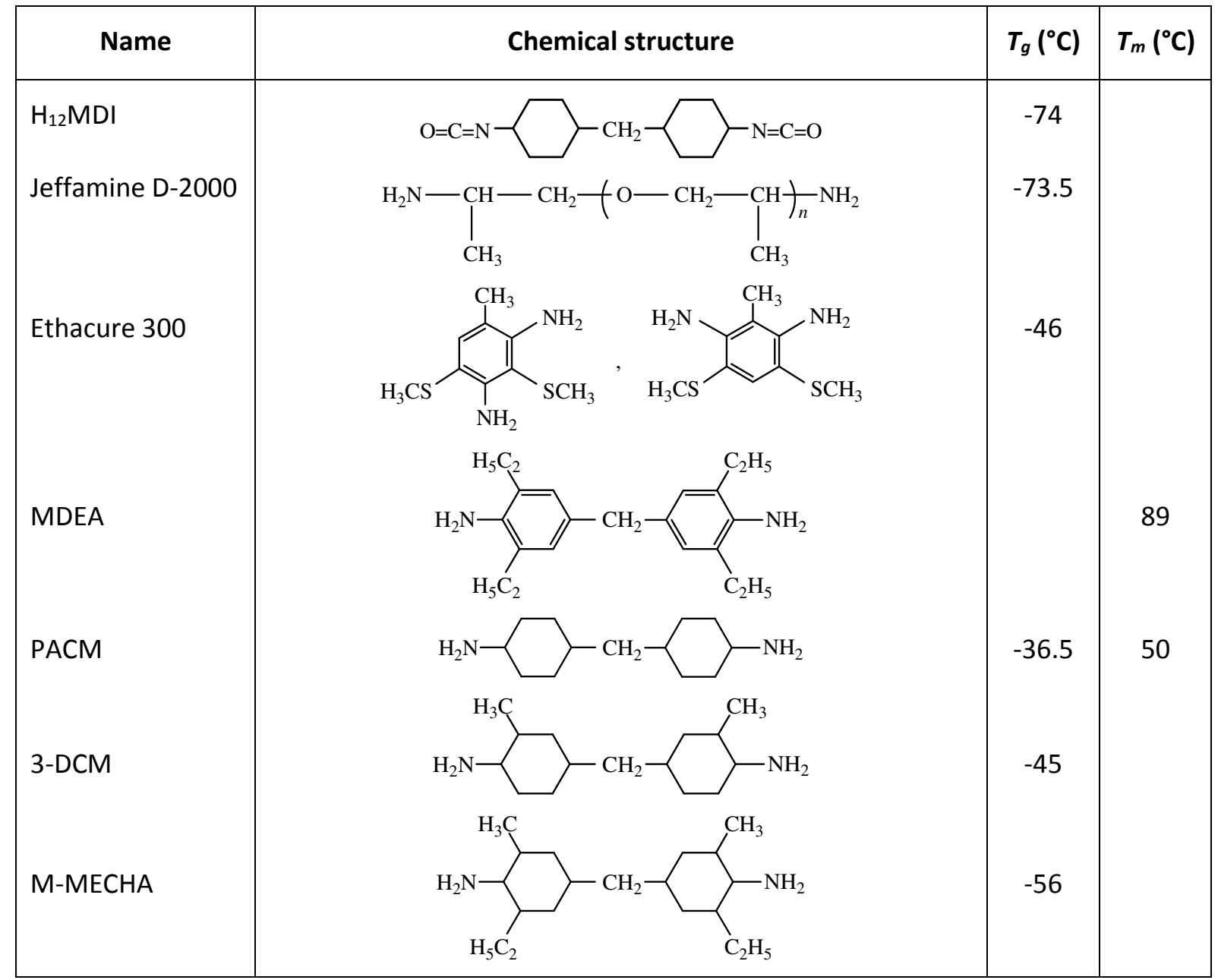

\section{Segmented Polyurea Synthesis}

It should be noted that the $\mathrm{NCO} / \mathrm{NH}_{2}$ ratio was always chosen equal to 1.1 to be sure of the reaction of all $\mathrm{NH}_{2}$ functions, even if any side reaction of $\mathrm{NCO}$ groups occurred. More precisely, the overall composition of all mixtures was, for example, one Jeffamine molecule for 3.3 diisocyanate molecules and two chain extender molecules for the said $1 / 3 / 2$ stoichiometry.

Polyureas based on aromatic diamines were synthesized by a one-stage bulk polycondensation; the diamine chain extender was dissolved in Jeffamine D-2000 either at room temperature (Ethacure 300) or at $90^{\circ} \mathrm{C}$ (MDEA). If necessary, $0.04 \mathrm{wt} \%$ DBTDL was added. The diamines were then rapidly mixed with $\mathrm{H}_{12} \mathrm{MDI}$ at room temperature and the reacting mixture was cast in a mold where it was reacted at $80^{\circ} \mathrm{C}$ for $12 \mathrm{~h}$ and then postcured at $150^{\circ} \mathrm{C}$ for $2 \mathrm{~h}$ to ensure reaction completion.

Without a RIM machine, polyureas based on cycloaliphatic diamines (PACM, 3-DCM, or M- MECHA) had to be synthesized by solution polycondensation in THF because of their high reactivity. Uncatalyzed syntheses were carried out using a one-stage procedure, that is, by dissolving all the reactants in THF and reacting at $25^{\circ} \mathrm{C}$ for $24 \mathrm{~h}$. Catalyzed syntheses were made by a two-stage polycondensation method: in the first stage an isocyanate terminated prepolymer was prepared by reacting Jeffamine D-2000 and $\mathrm{H}_{12} \mathrm{MDI}$ in bulk at $80^{\circ} \mathrm{C}$ for $2 \mathrm{~h}$. After cooling back to room temperature 
and dissolving the prepolymer in THF, the catalyst and the chain extender were added and the reaction was carried on for $24 \mathrm{~h}$.

In all cases the polymers were dried at $80^{\circ} \mathrm{C}$ for $12 \mathrm{~h}$ to ensure complete solvent removal and were finally pressed in a mold ( 100 bars, $\left.150^{\circ} \mathrm{C}\right)$ for $30 \mathrm{~min}$.

For every synthesis the end of the reaction was assumed to be reached when the FTIR spectrum showed a total disappearance of the isocyanate peak at $2270 \mathrm{~cm}^{-1}$.

\section{Polymer Characterization}

The average molar masses and their distributions were determined by size exclusion chromatography (SEC) using a Waters chromatograph with a 6000A pump, U6K injector, and double detection (UV at $\lambda=254 \mathrm{~nm}$ and differential refractometer R401). The eluent used was THF and the separation was carried out on four microstyragel columns $\left(10^{5}, 10^{4}, 10^{3}\right.$, and $\left.500 \AA\right)$. The molar mass calibration curve was obtained from polystyrene standards.

Pure hard segment polyureas have a high degree of crystallinity and a strong cohesion due to the hydrogen bonds, so that they are very little soluble in most polar solvents. A solubilization method generally used for semicrystalline polyamide ${ }^{24,25}$ was applied to polyureas. In this way, solubilization in THF is possible by a chemical modification using trifluoroacetic anhydride (TFA), which destroys hydrogen bonds. Solutions of polyetherureas in THF were prepared with a large excess TFA. The reaction scheme is<smiles>[R]NC(=O)N[C+]C(C(=O)OC)C(=O)OC</smiles><smiles>[R]NC(=O)N(C)C(=O)C(F)(F)F</smiles>

This modification is not complete and is very slow for polyurethanes. ${ }^{26,27}$ The same observation was made for our polyureas, although the solutions were warmed to $40^{\circ} \mathrm{C}$ for 3 days to accelerate the reaction, but a partial modification is sufficient to dissolve the samples in THF.

Glass transition temperatures $\left(T_{g}\right)$ were measured with a differential scanning calorimeter (Mettler TA3000) on 10-20 mg samples under dry nitrogen, using a heating rate of $7.5^{\circ} \mathrm{C} / \mathrm{min} . T_{g}$ was taken as the onset of the phenomenon.

The dynamic mechanical properties were measured on a Rheometrics RSA II apparatus at a frequency of $1 \mathrm{~Hz}$. For compression tests, cylindrical samples of $10 \times 10 \mathrm{~mm}$ (length $\times$ diameter) were used. The heating rate was $3^{\circ} \mathrm{C} / \mathrm{min}$. Rectangular bars $(1.5 \times 5 \times 30 \mathrm{~mm})$ were cut from the molded plaques for tensile testing. 
Uniaxial stress-strain experiments were carried out at room temperature with a M30K tensile testing apparatus (JJ Instruments) with a crosshead speed of $50 \mathrm{~mm} / \mathrm{min}$. Samples were cut with an NF 51034 die and had a gauge length of $20 \mathrm{~mm}$.

\section{RESULTS AND DISCUSSION}

\section{Hard Segment Synthesis and Characterization}

The selection of the most suitable solvent was studied with $\left(-\mathrm{H}_{12} \mathrm{MDI}-\mathrm{MDEA}-\right)_{n}$ hard segments. The role of the solvent is to provide an inert medium in which the reactants and the resulting polyureas should remain quite soluble. Due to the high polarity of polyureas, only a few polar solvents (DMAc, DMF, or NMP) were found to be suitable choices. In fact, precipitation due to the increase in the molar mass and/or to crystallization generally stopped the reaction within a few hours and resulted in low molar masses and broad molar mass distributions, whatever the solvent (DMAc, DMF, or NMP).

SEC chromatograms of TFA-modified hard segments are shown in Figure 1. Peak 1 corresponds to the residual diamine monomer MDEA; peaks 2, 3, and higher can be attributed to $i$-mers of the hard polyurea. The negative peak observed on every chromatogram (with an elution time of $28 \mathrm{~min}$ ) corresponds to the excess TFA left from the chemical modification of the polymer. The data summarized in Table II show that the most complete reaction was achieved using DMF, which also had the lowest boiling point (and so was the easiest to take off); thus, it was subsequently used for all the hard segment syntheses.

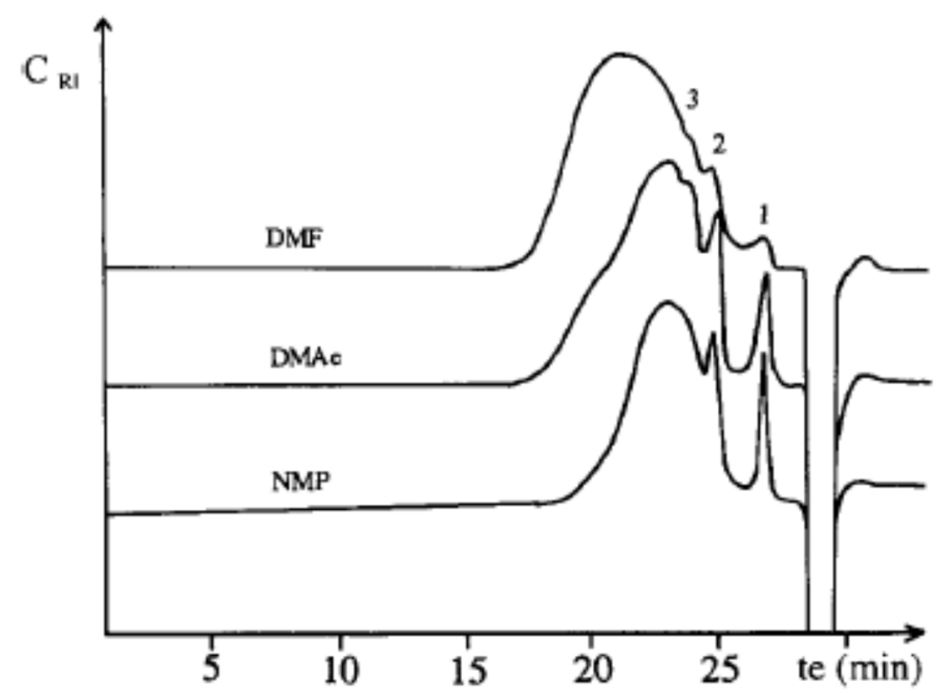

Figure 1 SEC chromatograms obtained for TFA-modified $\left(-\mathrm{H}_{12} \mathrm{MDI}-\mathrm{MDEA}-\right)_{n}$ hard segments synthesized in various solvents at $60^{\circ} \mathrm{C}$. 
Table II SEC data measured for TFA-modified $\left(-\mathrm{H}_{12} \mathrm{MDI}-\mathrm{MDEA}-\right)_{n}$ hard segments synthesized in several solvents at $60^{\circ} \mathrm{C}$

\begin{tabular}{|c|c|c|c|c|c|}
\hline Solvent & $\overline{\boldsymbol{M}_{\boldsymbol{n}}(\mathbf{g} / \mathbf{m o l})^{\mathbf{a}}}$ & $\overline{\boldsymbol{M}_{\boldsymbol{w}}} \mathbf{( g / \mathbf { m o l } ) ^ { \mathbf { a } }}$ & $\boldsymbol{I}_{\boldsymbol{p}}$ & $\begin{array}{c}\text { Residual } \\
\text { amine (\%) }\end{array}$ & $\boldsymbol{i}$-mer (\%) \\
\hline DMAc & 3500 & 11,000 & 3.1 & 7.3 & 13.1 \\
NMP & 3500 & 6900 & 2.0 & 10.3 & 13.1 \\
DMF & 4600 & 13,500 & 2.9 & 2.4 & 8.5 \\
\hline
\end{tabular}

a Polystyrene calibration, after TFA modification.

${ }^{\mathrm{b}}$ Evaluated by the relative area of peak 1.

${ }^{\mathrm{c}}$ Evaluated by the relative area of peak 2 .

Table II shows that the amine monomer was not completely reacted, which explains the molar mass distribution obtained. The existence of residual diamine reveals that under such conditions the reaction was never complete. This can be explained by the competition between polycondensation and an early hard segment crystallization resulting in a two-phase off-stoichiometry system.

Bonart et al. ${ }^{28}$ suggested a 3-dimensional hydrogen bonding between hard segments where two urea $-\mathrm{NH}-$ groups are bonded to one urea carbonyl in a nonplanar 3-dimensional conformation. To prevent crystallization, or at least to decrease the crystallization rate, we made some syntheses in the presence of $\mathrm{LiCl}$. Different authors ${ }^{11,13,29}$ showed that the effect of added lithium salts was to destroy hydrogen bonds of polyetherurethane ureas in DMF. ${ }^{11}$<smiles></smiles>

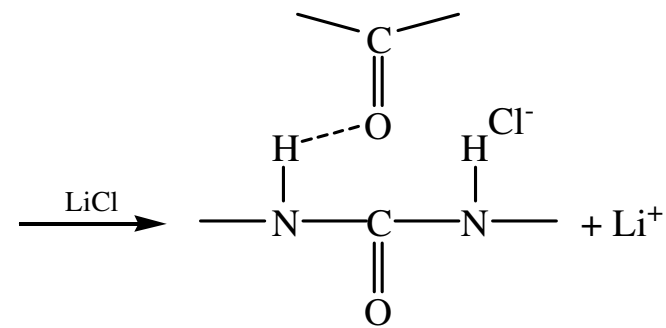

Very little data is available from the literature about the effect of LiCl on the solubility of pure hard segments. Lee and $\mathrm{Ko}^{11}$ prepared 4,4'-diphenylmethanediisocyanate (MDI)/4,4'-diaminodi phenylmethane (DDM) hard segments in DMF with $0.5 \mathrm{wt} \% \mathrm{LiCl}$, which apparently were not soluble. In our case the only solution that remained clear throughout the reaction, although the polymer was still not completely soluble, was obtained with $\left(-\mathrm{H}_{12} \mathrm{MDI}-\mathrm{MDEA}-\right)_{n}$ hard segments synthesized in NMP with $5 \mathrm{wt} \% \mathrm{LiCl}$ at $80^{\circ} \mathrm{C}$. In any other case precipitation was always observed.

The effect of $\mathrm{LiCl}$ on the amine/isocyanate reaction kinetics at $80^{\circ} \mathrm{C}$ in DMF was studied by FTIR by monitoring the disappearance of the NCO peak. Figure 2 depicts the evolution of NCO conversion with time. In DMF solution the reaction rate is low; the addition of $\mathrm{LiCl}$ seems to slow down the amine/isocyanate reaction. This may be attributed to a decrease in amine reactivity because of $\mathrm{LiCl}$.

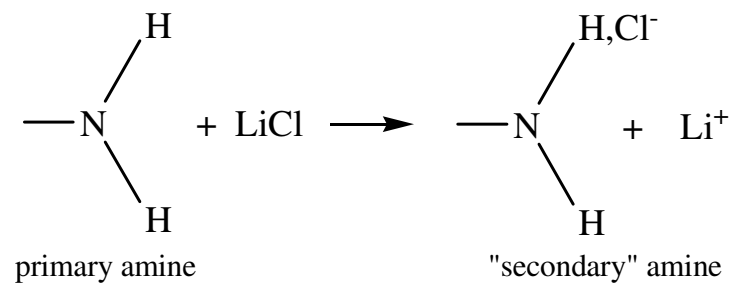




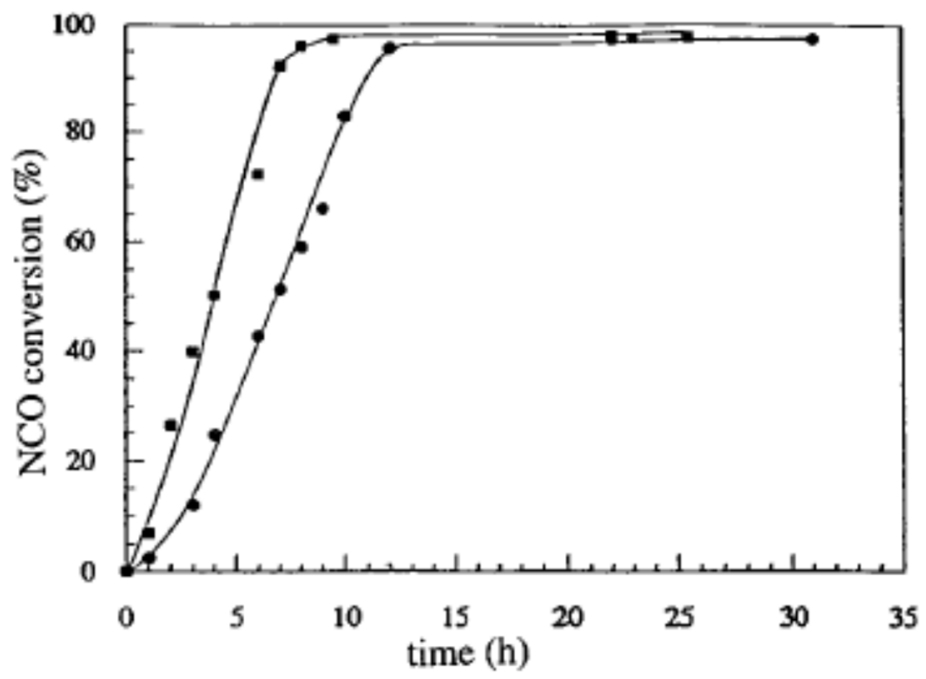

Figure 2 Kinetics of MDEA/ $\mathrm{H}_{12} \mathrm{MDI}$ reaction at $80^{\circ} \mathrm{C}$ in DMF (concentration, $17 \mathrm{wt} \%$ ) obtained from FTIR data. (O) NCO conversion with $5 \% \mathrm{LiCl}$ ( $(\square)$ NCO conversion without LiCl.

By introducing $\mathrm{LiCl}$ during the synthesis, we intended to decrease the crystallization rate; but in fact, we also decreased the reaction rate. A compromise might be found, but it turned out that $\mathrm{LiCl}$ had little or no effect on average molar masses, which were always very low; thus, its use was given up.

Figure 3 shows typical chromatograms obtained for TFA-modified polyurea hard segments. Data corresponding to these chromatograms are listed in Table III. $\left(-\mathrm{H}_{12} \mathrm{MDI}-\text { Ethacure } 300-\right)_{n}$ hard segments were synthesized by bulk polycondensation at $80^{\circ} \mathrm{C}$, which probably gives a more cohesive material than solution polycondensation and can explain why these hard segments were not completely soluble in THF, even after modification by TFA. In any case, hard segments based on aromatic diamines, $\left(-\mathrm{H}_{12} \mathrm{MDI}-\mathrm{MDEA}-\right)_{n}$ and $\left(-\mathrm{H}_{12} \mathrm{MDI}-\text { Ethacure } 300-\right)_{n}$, showed low molar masses and contained residual diamine monomer. On the other hand, $\left(-\mathrm{H}_{12} \mathrm{MDI}-\mathrm{PACM}-\right)_{n}$ and $\left(-\mathrm{H}_{12} \mathrm{MDI}-3-\mathrm{DCM}-\right)_{n}$ had no residual diamine monomer and higher molar masses in contrast to $\left(-\mathrm{H}_{12} \mathrm{MDI}-\mathrm{M}-\mathrm{MECHA}-\right)_{n}$ hard segments. 


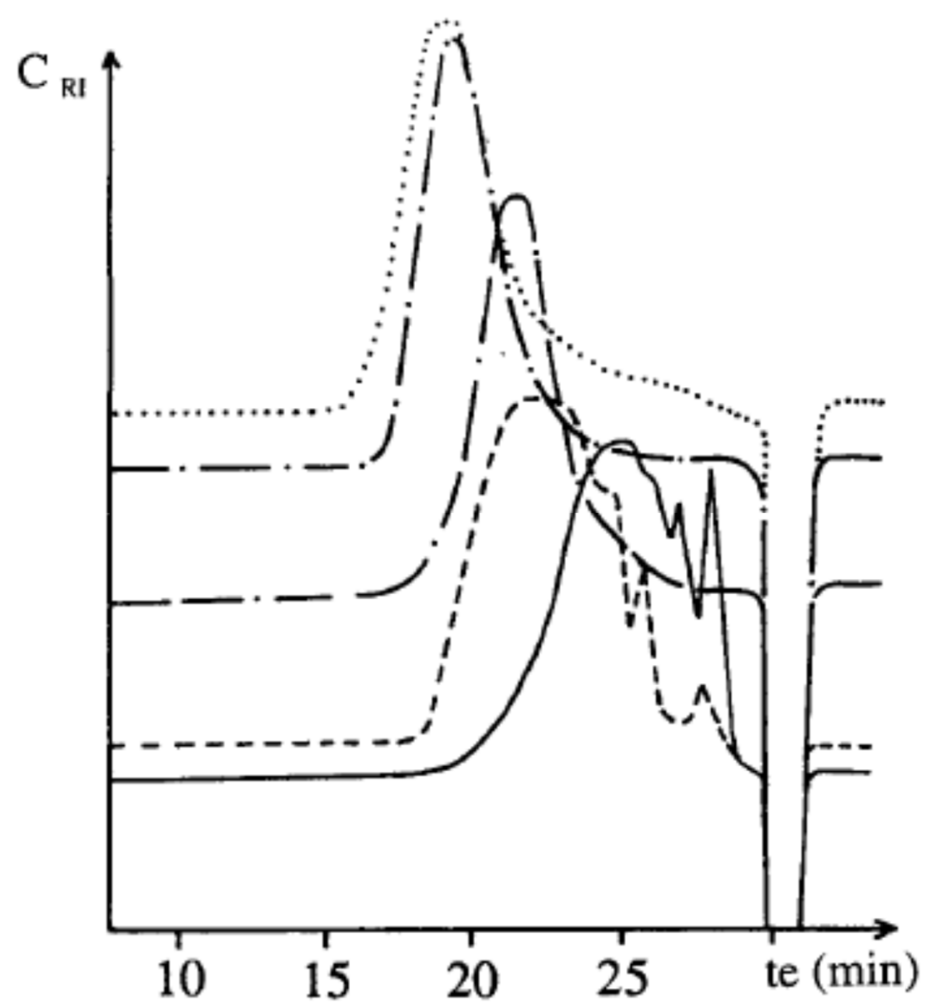

Figure 3 SEC chromatograms of polyurea hard segments after TFA modification: $(--)\left(-\mathrm{H}_{12} \mathrm{MDI}-\right.$ Ethacure 300- $)_{n}$, bulk polycondensation (soluble fraction); (- - ) (- $\left.\mathrm{H}_{12} \mathrm{MDI}-\mathrm{MDEA}-\right)_{n}$, solution polycondensation; (.-.) $\left(-\mathrm{H}_{12} \mathrm{MDI}-3-\mathrm{DCM}-\right)_{n}$, solution polycondensation in DMF; (. . .) ($\left.\mathrm{H}_{12} \mathrm{MDI}-\mathrm{PACM}-\right)_{n}$, solution polycondensation in DMF; $(--.)\left(-\mathrm{H}_{12} \mathrm{MDI}-\mathrm{M}-\mathrm{MECHA}-\right)_{n}$, solution polycondensation in DMF.

We concluded that the diamine structure, aliphatic or aromatic, led to very different reactivities but the hard segment synthesis was nevertheless mostly controlled by the competition between the kinetics of crystallization of the forming hard segments and polycondensation kinetics. We imagined that with aromatic diamines crystallization was faster than polycondensation and occurred in the first steps of the reaction; then polycondensation was blocked. In the case of nonhindered cycloaliphatic diamines (PACM or 3-DCM), which are much more reactive, the crystallization rate of the hard segments was lower than their polycondensation rate so that the amine/isocyanate reaction could reach a higher NCO conversion. The intermediary behavior of the last cycloaliphatic diamine $\mathrm{M}$ $\mathrm{MECHA}$, with a high steric hindrance, can be explained in the same way.

Thermal analysis confirmed this hypotheses. All the polyurea hard segments showed high melting temperatures $\left(T_{m} 230-360^{\circ} \mathrm{C}\right.$, see Table III). This result explains the difficulties encountered in synthesizing polyureas by classical ways in bulk or in solution. To avoid hard segment crystallization, it would be necessary to react $\mathrm{H}_{12} \mathrm{MDI}$ with the diamine above the melting temperature of the final hard segment. But this is quite impossible because of the too fast reaction and also the thermal degradation that would certainly occur just after melting.

Very high values were also found for the melting enthalpy $\left(\Delta H_{m}=55-153 \mathrm{~kJ} / \mathrm{mol} \mathrm{H}_{12} \mathrm{MDI}\right)$ as compared to classical polyurethane hard segments based on $\mathrm{MDI}$ and 1,4-butanediol (BDO) ( $\Delta H_{m}$ in the range 4$73 \mathrm{~kJ} \mathrm{~mol} \mathrm{MDI}$ ). ${ }^{30}$ These results denote the high degree of crystallinity of polyurea hard segments. It 
appears in Table III that values of $\Delta H_{m}$ increase with increasing diamine reactivity, or rather with the molar mass of the considered hard segment. This reveals that the presence of too many chain ends can prevent the polymer chains from organizing themselves correctly. The highest degree of crystallinity should thus be obtained with polyurea hard segments deriving from cycloaliphatic diamines $\left(\Delta H_{m}>200 \mathrm{~J} / \mathrm{g}\right)$. Among them, the less sterically hindered PACM provides the highest $\Delta H_{m}$ $(324 \mathrm{~J} / \mathrm{g})$ and the highest degree of crystallinity.

Table III SEC characterization and thermal properties of hard segments based on $\mathrm{H}_{12} \mathrm{MDI}$ (DMF solution polycondensation, $T=60^{\circ} \mathrm{C}$ )

\begin{tabular}{|c|c|c|c|c|c|c|}
\hline Structure & $\begin{array}{c}\overline{M_{n}} \\
(\mathrm{~g} / \mathrm{mol})^{\mathrm{a}, \mathrm{b}}\end{array}$ & $\begin{array}{c}\overline{M_{w}} \\
(\mathrm{~g} / \mathrm{mol})^{\mathrm{a}, \mathrm{b}}\end{array}$ & $I_{p}$ & $\begin{array}{l}\text { Residual } \\
\text { diamine } \\
\text { (area \%) }\end{array}$ & $T_{m}\left({ }^{\circ} \mathrm{C}\right)$ & $\begin{array}{c}\Delta H_{m} \\
(\mathrm{~kJ} / \mathrm{mol} \\
\left.\mathrm{H}_{12} \mathrm{MDI}\right)\end{array}$ \\
\hline$\left(-\mathrm{H}_{12} \mathrm{MDI}-\text { Ethacure } 300-\right)_{n}$ & $2500^{c}$ & $21,000^{c}$ & $8.4^{\mathrm{c}}$ & 2.0 & 233 & 55 \\
\hline$\left(-\mathrm{H}_{12} \mathrm{MDI}-\mathrm{MDEA}-\right)_{n}$ & 4600 & 13,500 & 2.9 & 2.4 & 350 & 82 \\
\hline$\left(-\mathrm{H}_{12} \mathrm{MDI}-\mathrm{M}-\mathrm{MECHA}-\right)_{n}$ & 5800 & 12,600 & 2.2 & 0 & 343 & 145 \\
\hline$\left(-\mathrm{H}_{12} \mathrm{MDI}-3-\mathrm{DCM}-\right)_{n}$ & 16,100 & 36,400 & 2.3 & 0 & 343 & 129 \\
\hline$\left(-\mathrm{H}_{12} \mathrm{MDI}-\mathrm{PACM}-\right)_{n}$ & 11,650 & 54,300 & 4.7 & 0 & 350 & 153 \\
\hline
\end{tabular}

a Polystyrene calibration.

${ }^{\mathrm{b}}$ After modification by TFA.

c Soluble fraction.

Finally, the high stiffness and the high degree of crystallinity of polyurea hard segments did not allow the detection of any glass transition by DSC. Only the $T_{g}$ of $\left(-\mathrm{H}_{12} \mathrm{MDI}-\text { Ethacure } 300-\right)_{n}$ hard segments could be estimated by dynamic compression; all other hard segments prepared in solution $\left[\left(-\mathrm{H}_{12} \mathrm{MDI}-\mathrm{MDEA}-\right)_{n}, \quad\left(-\mathrm{H}_{12} \mathrm{MDI}-\mathrm{PACM}-\right)_{n}, \quad\left(-\mathrm{H}_{12} \mathrm{MDI}-3-\mathrm{DCM}-\right)_{n}, \quad\right.$ and $\quad\left(-\mathrm{H}_{12} \mathrm{MDI}-\mathrm{M}-\right.$ MECHA- $)_{n}$ ] were powders that could not be tested by dynamic mechanical analysis. The glass transition of $\left(-\mathrm{H}_{12} \mathrm{MDI}-\text { Ethacure } 300-\right)_{n}$ occurred at approximately $220^{\circ} \mathrm{C}$. This illustrates that the $T_{g}$ of linear polyureas can reach values much higher than that of classical linear polyurethane hard segments $\left(T_{g} \approx 90-120^{\circ} \mathrm{C}\right) .{ }^{27}$

\section{Synthesis and Characterization of Segmented Polyureas}

The segmented polyureas based on aromatic diamines were synthesized by a one-step bulk polycondensation, with or without catalyst. The polymers based on cycloaliphatic diamines were synthesized by solution polycondensation. Because the number average molar masses, $\overline{M_{n}}$, were neither influenced by the nature of the solvent (THF or DMF) nor by the experimental procedure (oneor two-stage), these polyureas were prepared in THF (dilution $7 \mathrm{wt} \%$ ) with a one-stage procedure for uncatalyzed syntheses and a two-stage procedure when DBTDL was used. In any case, clear materials were obtained but all the segmented polyureas nevertheless needed TFA modification to become perfectly soluble in THF for SEC measurements. Table IV lists the molar mass values obtained for the five types of segmented polyureas. 
Figure 4 displays SEC chromatograms corresponding to the segmented polyureas. All uncatalyzed polymers exhibited low number average molar masses and sometimes high polydispersity indexes $\left(I_{p}\right)$. Every chromatogram particularly presents series of very low molar masses that are eluted beyond $25 \mathrm{~min}$. For D-2000/ $\mathrm{H}_{12} \mathrm{MDI} /$ Ethacure 300, an isolated high peak was present at $27.5 \mathrm{~min}$ and can be attributed to residual Ethacure monomer. The other low molar masses do not correspond to any residual monomer. The comparison between the chromatograms of segmented polyureas and that of the initial Jeffamine D-2000 oligomer reveals that these very low molar mass species are eluted after the starting soft segment. Consequently, they can be attributed to isolated hard segments (i.e., not chemically linked to any soft segment). Willkomm et al. ${ }^{1}$ also showed by SEC analysis of linear RIM copolyureas [based on Jeffamine D-2000, MDI, and 3,5-diethyltoluene-2,4-diamine (DETDA)] the presence of hard segments with molar mass values as low as $600 \mathrm{~g} / \mathrm{mol}$. For our polymers, estimations of the isolated hard segment (I-HS) amounts are reported in Table IV (area of I-HS/total area of the chromatogram). It can be seen that high polydispersity indexes are in fact associated with high I-HS percentages.

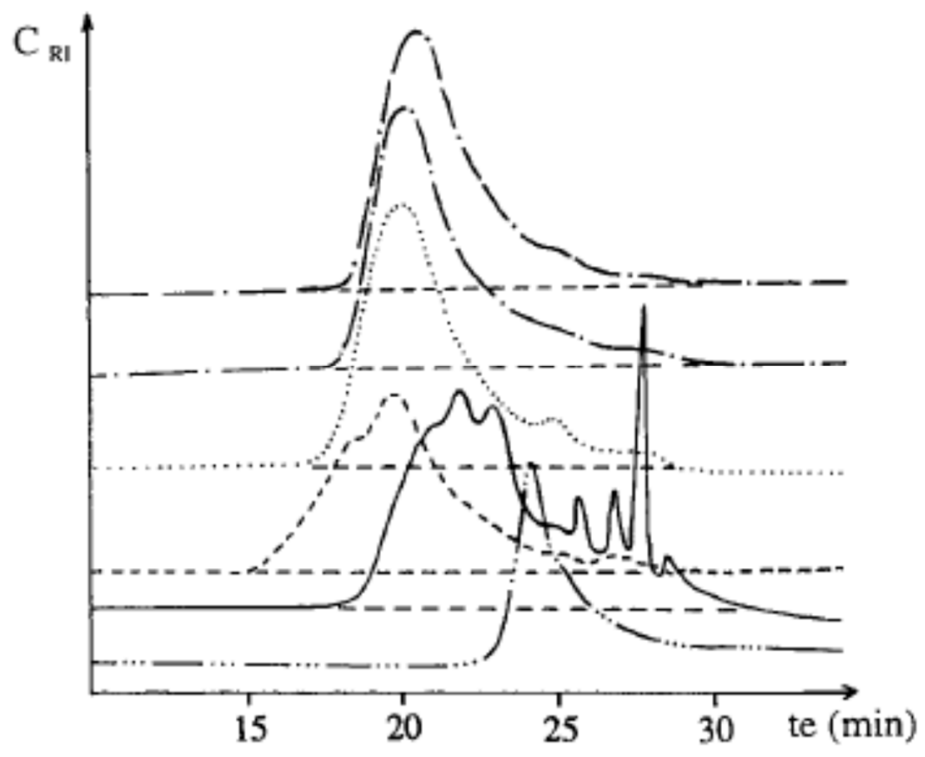

Figure 4 SEC chromatograms of uncatalyzed segmented polyureas (after postcuring $2 \mathrm{~h}$ at $150^{\circ} \mathrm{C}$ ): (- . . .) initial unreacted Jeffamine D-2000; (- ) D-2000/ $\mathrm{H}_{12} \mathrm{MDI} /$ Ethacure 300; (- - -)

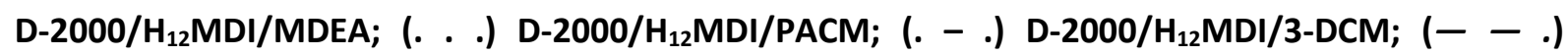
D-2000/H $\mathrm{H}_{12} \mathrm{MDI} / \mathrm{M}-\mathrm{MECHA}$. 
Table IV Average molar masses, molar mass distributions, and thermal characteristics of segmented polyureas

\begin{tabular}{|c|c|c|c|c|c|c|c|c|c|c|}
\hline Segmented polyurea & $\begin{array}{c}\text { Hard } \\
\text { segment } \\
(\%)\end{array}$ & Synthesis procedure & $\begin{array}{c}\overline{M_{n}} \\
(\mathrm{~g} / \mathrm{mol})^{\mathrm{a}}\end{array}$ & $\begin{array}{c}\bar{M}_{w} \\
(\mathrm{~g} / \mathrm{mol})^{\mathrm{a}}\end{array}$ & $I_{p}$ & $\begin{array}{l}\text { I-HS } \\
(\%)^{b}\end{array}$ & $\begin{array}{l}T_{g}^{s} \\
\left({ }^{\circ} \mathrm{C}\right)\end{array}$ & $\begin{array}{c}T_{m} \\
\left({ }^{\circ} \mathrm{C}\right)\end{array}$ & $\begin{array}{l}\Delta H_{m} \\
(\mathrm{~J} / \mathrm{g})\end{array}$ & $\begin{array}{c}\Delta H_{m} \\
(\mathrm{~J} / \mathrm{g} H S)\end{array}$ \\
\hline D2000/ $\mathrm{H}_{12} \mathrm{MDI} /$ Ethacure 300 & 38 & $\begin{array}{c}\text { Bulk } \\
\text { Bulk, catalyzed }\end{array}$ & $\begin{array}{l}7600 \\
3500\end{array}$ & $\begin{array}{c}118,200 \\
19,000\end{array}$ & $\begin{array}{c}15.6 \\
5.4\end{array}$ & $\begin{array}{l}36 \\
19\end{array}$ & $\begin{array}{l}-61 \\
/ c\end{array}$ & \multicolumn{3}{|c|}{$\begin{array}{l}\text { Amorphous } \\
\text { Amorphous }\end{array}$} \\
\hline \multirow{3}{*}{$\mathrm{D} 2000 / \mathrm{H}_{12} \mathrm{MDI} / \mathrm{MDEA}$} & \multirow{3}{*}{42} & Bulk & 8300 & 71,600 & 8.6 & 10 & -61 & 320 & 52 & 124 \\
\hline & & Bulk, catalyzed & 8500 & 29,800 & 3.5 & 11 & $/^{\mathrm{c}}$ & \multirow{2}{*}{\multicolumn{3}{|c|}{$\begin{array}{l}\text { Amorphous } \\
\text { Amorphous }\end{array}$}} \\
\hline & & Solution, catalyzed & 3350 & 14,300 & 4.3 & 22 & $/^{\mathrm{c}}$ & & & \\
\hline \multirow[t]{2}{*}{ D2000/H $\mathrm{H}_{12} \mathrm{MDI} / \mathrm{M}-\mathrm{MECHA}$} & \multirow[t]{2}{*}{41} & Solution & 9000 & 27,000 & 3.0 & 10 & -61 & 341 & 137 & 334 \\
\hline & & Solution, catalyzed & 24,400 & 53,300 & 2.2 & 0 & -61 & 341 & 126 & 307 \\
\hline \multirow[t]{2}{*}{$\mathrm{D} 2000 / \mathrm{H}_{12} \mathrm{MDI} / 3-\mathrm{DCM}$} & \multirow[t]{2}{*}{39} & Solution & 11,800 & 32,100 & 2.7 & 11 & -61 & 343 & 148 & 379 \\
\hline & & Solution, catalyzed & 25,500 & 52,500 & 2.1 & 0 & -61 & 343 & 117 & 300 \\
\hline \multirow[t]{2}{*}{ D2000/H ${ }_{12} \mathrm{MDI} / \mathrm{PACM}$} & \multirow[t]{2}{*}{38} & Solution & 9500 & 34,550 & 3.6 & 9 & -61 & 337 & 129 & 339 \\
\hline & & Solution, catalyzed & 34,200 & 84,500 & 2.5 & 0 & -61 & 337 & 131 & 345 \\
\hline
\end{tabular}

I-HS, isolated hard segment.

${ }^{\text {a }}$ According to a polystyrene calibration, after TFA modification.

${ }^{b}$ Estimated by the relative area of the I-HS peaks in the chromatograms.

${ }^{\mathrm{c}}$ Not clearly visible in DSC curves 
The chromatograms obtained for polyureas resulting from a catalyzed synthesis are presented in Figure 5. It can be seen that contrary to the uncatalyzed procedure, catalyzed polyureas based on cycloaliphatic diamines exhibited much higher number average molar masses while the polydispersity index remained rather low (2.0-2.5). Catalyzed polyureas deriving from aromatic diamines and prepared by bulk or solution polycondensation showed lower molar masses; but their polydispersity index was still lower than that of their uncatalyzed counterpart (3.6-5.4) and less isolated hard segments were detected (11-19\%, see Fig. 5).

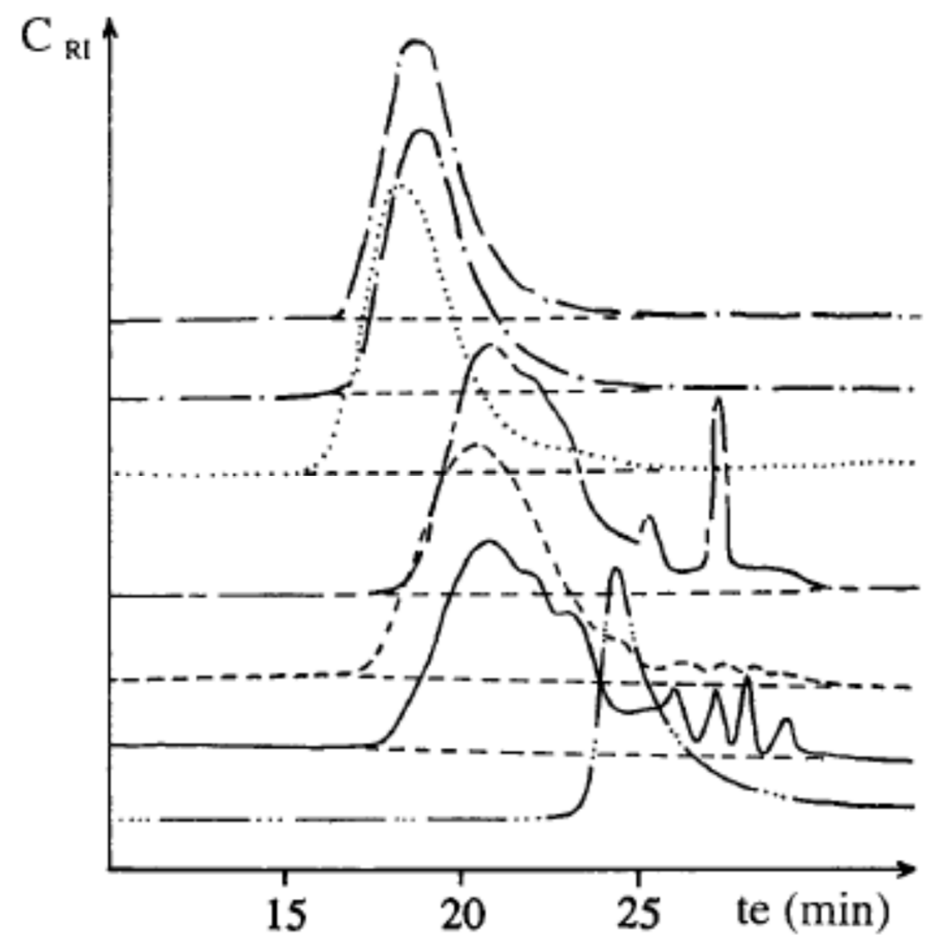

Figure 5 SEC chromatograms of catalyzed segmented polyureas: $(-\ldots)$ initial unreacted Jeffamine

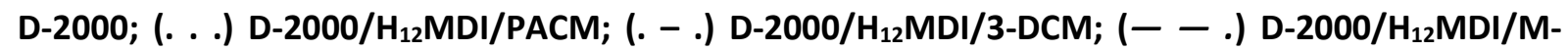
MECHA; (- ) D-2000/H $\mathrm{H}_{12} \mathrm{MDI} /$ Ethacure 300; (- - -) D-2000/H $\mathrm{H}_{12} \mathrm{MDI} / \mathrm{MDEA}$, bulk polycondensation; $(--) \mathrm{D}-2000 / \mathrm{H}_{12} \mathrm{MDI} / \mathrm{MDEA}$, solution polycondensation.

DBTDL has been shown to have no or very little effect on the kinetics of the reaction between an aromatic amine ${ }^{31}$ or diamine ${ }^{32}$ and phenylisocyanate, in contrast to tertiary amines. In the literature the dibutyltin cation is reported to form a mixed complex with the isocyanate function and one or two hydroxyl groups in the case of urethane formation. ${ }^{33-35}$ The main requirements for an efficient catalysis are that the oxygen atom of the $\mathrm{OH}$ group, once coordinated, must remain sufficiently nucleophilic to bind to the isocyanate carbon and that the metal must not remain linked to the product after its formation. ${ }^{34}$ In our case a cycloaliphatic isocyanate function was reacted with an amine, either aromatic (Ethacure 300, MDEA) or cycloaliphatic (PACM, 3-DCM, M-MECHA), and was either sterically hindered or not (MDEA . M-MECHA . Ethacure 300 . 3-DCM . PACM). The formation of such a complex may also be possible with amines (as revealed by the catalytic effect observed with cycloaliphatic ones). If so, with aromatic (i.e. less nucleophilic) amines, the first condition might no longer be fulfilled, especially because the carbon atom of the cycloaliphatic isocyanate function is less electrophilic and no catalysis would be observed in this case. 
The worst distribution was that of $\mathrm{D}-2000 / \mathrm{H}_{12} \mathrm{MDI} /$ Ethacure uncatalyzed polyurea, which was very broad $\left(I_{p}=15.4\right)$ and had very low molar masses. This can be explained by the very low reactivity of Ethacure 300 , as seen for the $\left(-\mathrm{H}_{12} \mathrm{MDI}-\text { Ethacure } 300-\right)_{n}$ hard segment synthesis. In this case the reaction kinetics, even with an attempt to catalyze it, could not compete with the high crystallization rate of the hard segments. On the contrary, for uncatalyzed polyureas a better result was obtained with cycloaliphatic diamines that led to symmetrical mass distributions, although the average molar masses remained rather low. In these cases, the catalysis of the reaction allowed the kinetics to compete with the crystallization rate and the best molar mass distributions were obtained: $24,000<\overline{M_{n}}<34,000 \mathrm{~g} / \mathrm{mol} ; 53,000<\overline{M_{w}}<84,000 \mathrm{~g} / \mathrm{mol} ; 2.0<l_{p}<2.5$.

It was interesting to compare our SEC results with results from the literature. Indeed, the SEC eluents were different. Moreover, the real effects of TFA modification on molar mass values were not very well established in this particular case; a small shift in elution time might be induced.

Concerning polyureas based on aromatic diamines and prepared by bulk polycondensation, our results were in relatively good agreement with the literature. Willkomm et al. ${ }^{1}$ compared the properties of identical Jeffamine D-2000 linear copolyureas based on MDI/DETDA hard segments and synthesized by solution polycondensation ${ }^{14}$ or prepared by RIM. ${ }^{1}$ RIM polyureas, once analyzed by SEC in NMP (polystyrene standards), displayed significantly lower molar masses than polyureas obtained by solution polycondensation in NMP. Whatever the synthesis method, the polydispersity index was always in the 3.6-4.0 range. Thus, the bulk process, carried out by simple casting as in our case or by RIM, seems to lead to a broad molar mass distribution with low values of $\overline{M_{n}}$.

Concerning polyureas based on cycloaliphatic diamines prepared by solution polycondensation, our results were very different from the literature. With Jeffamine D-2000 polyureas based on MDI/DETDA hard segments and synthesized by a two-stage solution polycondensation in DMAc, Chen et al. ${ }^{14}$ obtained by SEC measurements in NMP (polystyrene calibration) values of $\overline{M_{w}}$ in the $76,000-160,000$ $\mathrm{g} / \mathrm{mol}$ range and $\overline{M_{n}}$ in the $21,000-44,000 \mathrm{~g} / \mathrm{mol}$ range, with $I_{p}$ values of 3.4-3.7. Thus, it seems that the use of a more reactive diisocyanate is favorable, presumably as far as the chain extender is concerned. It can be a way to allow the reaction to be faster than hard segment crystallization.

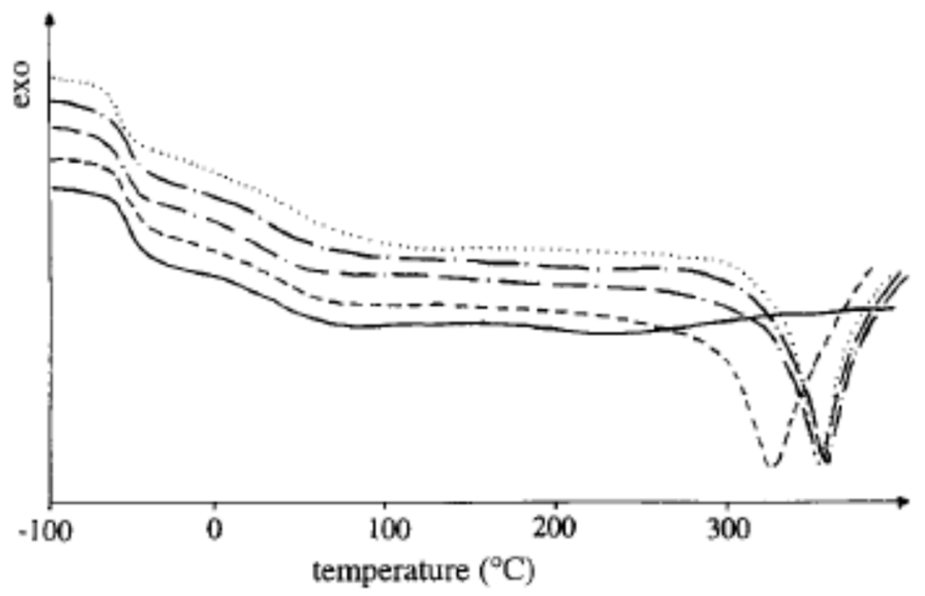

Figure 6 DSC curves obtained for segmented polyureas based on: (. . .) $\left(-\mathrm{H}_{12} \mathrm{MDI}-\mathrm{PACM}-\right)_{n}$ hard segments (catalyzed); (. - .) (- $\left.\mathrm{H}_{12} \mathrm{MDI}-3-\mathrm{DCM}-\right)_{n}$ hard segments (catalyzed); ( - . ) (- $\mathrm{H}_{12} \mathrm{MDI}-$ M-MECHA- $)_{n}$ hard segments (catalyzed); (- - -) (- $\left.-\mathrm{H}_{12} \mathrm{MDI}-\mathrm{MDEA}-\right)_{n}$ hard segments (uncatalyzed); $(--)\left(-\mathrm{H}_{12} \mathrm{MDI}-\text { Ethacure } 300-\right)_{n}$ hard segments (uncatalyzed). 
DSC curves (see Fig. 6) show a glass transition at $-61^{\circ} \mathrm{C}$, which corresponds to the glass transition temperature of the soft phase $\left(T_{g} \mathrm{~S}\right)$ of the segmented polyureas. The fact that all of our samples display the same $T_{g}$ for their soft phase (Table IV) means that the soft phases are quite pure and without dissolved hard segments. DSC curves also display no crystallization peak but display a melting peak at elevated temperature $\left(T_{m}=300-340^{\circ} \mathrm{C}\right)$ for all the segmented polyureas, which originates from the melting of the crystalline part of the hard phase. This means that crystallization of the hard segments occurred during the synthesis and could explain the formation of the I-HS observed on SEC curves whenever the reaction rate was too low. The fact that the melting enthalpies of pure hard segments are similar to those $\left(\Delta H_{m}, \mathrm{~J} / \mathrm{g}\right.$ hard segment) of the corresponding segmented polyureas denotes that in such materials the hard phase is organized like pure hard segments. Moreover, it can be seen in Table IV that $\left(\Delta H_{m}, \mathrm{~J} / \mathrm{g}\right.$ hard segment) values of uncatalyzed polyureas based on M-MECHA or 3-DCM are higher than those of their catalyzed counterparts, suggesting that the degree of crystallinity of the hard phase is higher when the noncatalyzed synthesis procedure is used, presumably because of the presence of some I-HS. On the contrary, chemical linkages between hard and soft domains would restrict the ability of the hard segment to crystallize. Such a phenomenon is already described in the literature on $\mathrm{MDI} / 1,4-\mathrm{BDO}$-based polyurethanes. ${ }^{36-38}$ These systems are reported to lead to early crystallization that prevents further reaction when no catalyst is used; catalyzed procedures enable reaction completion.

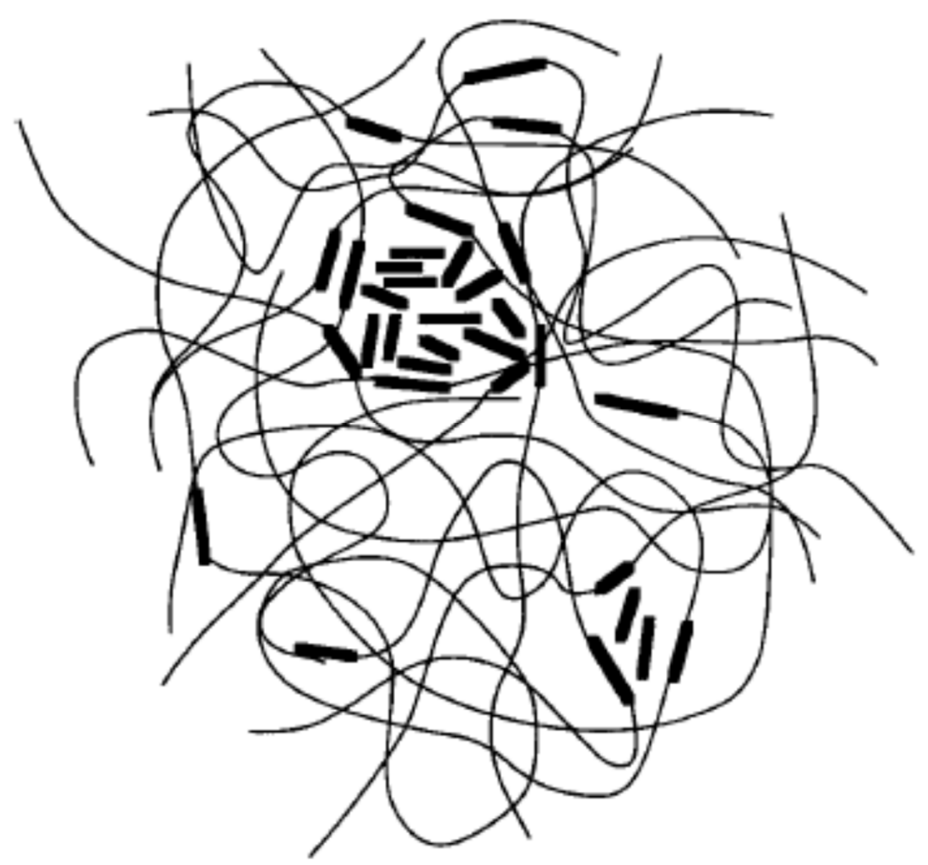

Figure 7 Schematic representation of the structure assumed for our uncatalyzed segmented polyureas.

The structure of our uncatalyzed segmented polyureas can be represented as in Figure 7: a soft segmented polyurea matrix with dispersed hard segments and rigid domains formed principally by isolated segment aggregates as the core, and some chain-extended hard segments as the shell to stabilize the interface. This structure results from the competition between hard segment crystallization and polycondensation kinetics during the synthesis. The first stage of polyurea synthesis would be the reaction of Jeffamine D-2000 with $\mathrm{H}_{12} \mathrm{MDI}$ (formation of an isocyanate terminated 
prepolymer), followed by chain extension through the reaction of terminal NCO groups and excess $\mathrm{H}_{12} \mathrm{MDI}$ with the diamine. Unfortunately and especially with aromatic diamines, the polycondensation second stage would be rapidly stopped by the hard segment crystallization, leading to low molar masses. This situation can be limited to some extent or even completely by use of a catalyst. In any case, the use of the more reactive cycloaliphatic diamines PACM and 3-DCM in a catalyzed process can be a good way to cope with this problem, because no isolated hard segments were observed for these reactive systems. Consequently, the materials prepared for mechanical characterization were obtained by catalyzed solution polycondensation for cycloaliphatic diamines and by noncatalyzed bulk polycondensation for aromatic diamines.

\section{Dynamic Mechanical Properties}

The storage modulus $E^{\prime}$ and dissipation factor $\tan \delta$ of a series of D-2000/ $\mathrm{H}_{12} \mathrm{MDI} / 3-\mathrm{DCM}$ segmented polyureas with different hard segment contents are plotted as a function of temperature in Figure 8. The low temperature loss peak as can be attributed to the backbone motion of the soft segment that accompanies its glass transition: the drop in $E^{\prime}$ is observed at $-63^{\circ} \mathrm{C}$, which is in good agreement with DSC values of $T_{g} S\left(-61^{\circ} \mathrm{C}\right)$. The difference between this value and the $T_{g}$ of pure Jeffamine D-2000 is due to the fact that the chain ends are linked to rigid urea groups. ${ }^{14}$ When the hard segment content increases, both the intensity and the width of the $\tan \delta$ relaxation increase whereas the temperature of the peak maximum does not change (see Table V).

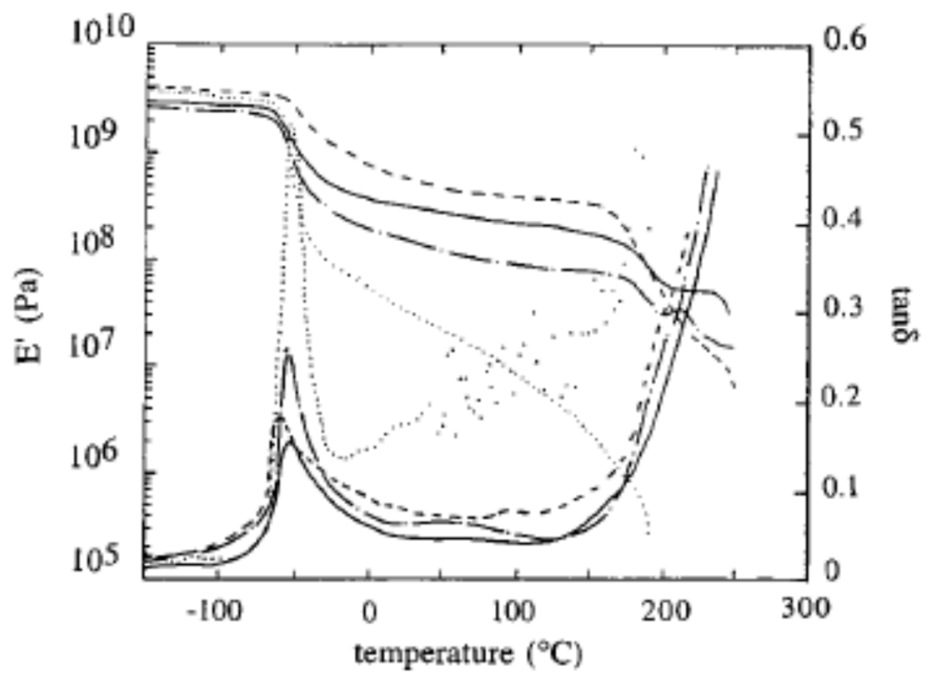

Figure 8 Storage modulus $E^{\prime}$ and loss factor $\tan \delta$ of $\mathrm{D}-2000 / \mathrm{H}_{12} \mathrm{MDI} / 3-\mathrm{DCM}$ polyureas with different hard segment content: (. . .) 28 wt \%; (. - .) 39 wt \%; (--) 47 wt \%; (- - -) 54 wt \%. 
Table V Dynamic mechanical properties of $\mathrm{D}-2000 / \mathrm{H}_{12} \mathrm{MDI} / 3-\mathrm{DCM}$ segmented polyureas as function of hard segment content

\begin{tabular}{|c|c|c|c|c|c|c|}
\hline $\begin{array}{c}\text { hard } \\
\text { segment } \\
\text { content (\%) }\end{array}$ & $\begin{array}{l}T_{\alpha}^{s} \\
\left({ }^{\circ} \mathrm{C}\right)^{\mathrm{a}}\end{array}$ & $\begin{array}{c}E_{c}^{\prime}\left(20^{\circ} \mathrm{C}\right) \\
(\mathrm{MPa})\end{array}$ & $\frac{E^{\prime}\left(20^{\circ} C\right)}{E^{\prime}\left(80^{\circ} C\right)}$ & $\begin{array}{c}T_{\alpha}^{h} \\
\left({ }^{\circ} \mathrm{C}\right)^{\mathrm{a}}\end{array}$ & $\begin{array}{c}\tan \delta \\
\text { peak } \\
\text { height }\end{array}$ & $\begin{array}{c}\tan \delta \text { peak height } \\
\text { (100\% soft segment) }\end{array}$ \\
\hline 28 & -63 & 35 & 2.5 & $\sim 150$ & 0.51 & 0.71 \\
\hline 39 & -63 & 154 & 1.6 & 180 & 0.26 & 0.43 \\
\hline 47 & -63 & 342 & 1.4 & 160 & 0.16 & 0.30 \\
\hline 54 & -63 & 615 & 1.5 & 160 & 0.11 & 0.20 \\
\hline
\end{tabular}

${ }^{\text {a }}$ Onset temperature for the drop of $E^{\prime}$.

At higher temperature tan $d$ increases and $E^{\prime}$ drops again (onset $\sim 160^{\circ} \mathrm{C}$ ). Numerous authors $\mathrm{s}^{2-4,19,22}$ agree to assign this relaxation, $\alpha_{h}$, to the glass transition of the hard domains, which in our case was not detectable by DSC. Between $\alpha_{s}$ and $\alpha_{\hbar}$ these segmented polyureas generally exhibit a rubbery plateau with a modulus $\left(E_{c}^{\prime}\right)$ increasing upon increasing hard segment content. On the contrary, for the lowest $\left(-\mathrm{H}_{12} \mathrm{MDI}-3-\mathrm{DCM}-\right)_{n}$ hard segment content $(28 \%)$, the rubbery modulus is low and keeps decreasing dramatically between the two relaxations. The hard domains that create a kind of filler effect reinforcing the soft phase (for hard segment contents of 39-54\%) are too few in this case. In addition, Wang and Cooper ${ }^{22}$ stated that more hard segments induced higher concentrations of urea groups whose hydrogen-bonded network enhanced intradomains of cohesion. In this respect, for hard segment contents higher than $28 \%$ the segmented polyureas show an almost horizontal rubbery plateau $\left[E^{\prime}\left(20^{\circ} \mathrm{C}\right) / E^{\prime}\left(80^{\circ} \mathrm{C}\right) \approx 1.5\right]$ up to $160-180^{\circ} \mathrm{C}$, but still with a high dissipated energy (tan $\delta^{\sim} 0.05-$ 0.08 , depending on the hard segment content).

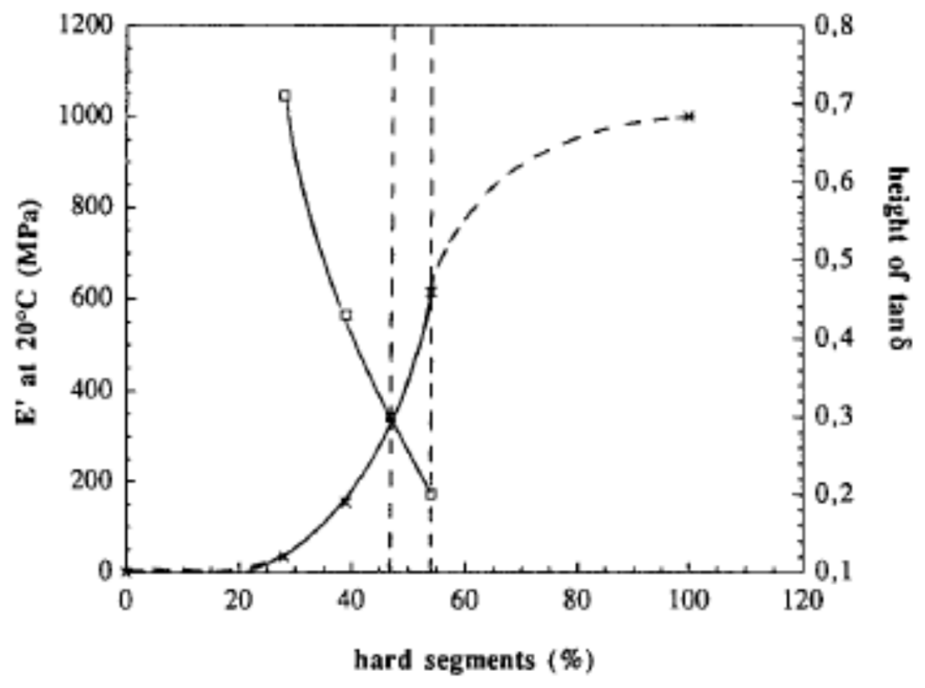

Figure 9 Variations of $(\times) E^{\prime}\left(20^{\circ} \mathrm{C}\right)$ and $(\square)$ the height of the tan $\delta$ peak for D-2000/ $\mathrm{H}_{12} \mathrm{MDI} / 3-\mathrm{DCM}$ polyureas as a function of hard segment content.

$E^{\prime}\left(20^{\circ} \mathrm{C}\right)$ and $\tan \delta$ peak height (normalized to $100 \%$ soft segments) have been plotted versus hard segment content in Figure 9. The height of $\tan \delta$ peak decreases with increasing hard segment amount. Assuming that $E^{\prime}\left(20^{\circ} \mathrm{C}\right)=1 \mathrm{MPa}$ for a $100 \%$ soft segment and $1 \mathrm{GPa}$ for a $100 \%$ hard segment, the 
variation of $E^{\prime}$ follows a sigmoid curve. The inflexion probably denotes phase inversion, which would thus occur between 47 and $54 \%$ hard segments; the polyurea containing $54 \%$ hard segments would be composed of a soft phase dispersed in a hard matrix.

$E^{\prime}$ and $\tan \delta$ are represented as a function of temperature in Figure 10 for aromatic chain extenders and in Figure 11 for cycloaliphatic ones. The low temperature relaxation peak, $\alpha_{s}$, attributed to the soft domain, is most intense in the case of Ethacure 300 . Moreover, the rubbery plateau is very short and the modulus decreases dramatically $\left[E^{\prime}\left(20^{\circ} \mathrm{C}\right) / E^{\prime}\left(80^{\circ} \mathrm{C}\right)=3.3\right]$. These two features can be related to the high proportion of isolated hard segments ( $36 \%$, see Table IV) in this material. Because most of the hard segments are not chemically linked to the soft matrix, they do not seem to play their filler role any more. The polyurea obtained from MDEA, which contains only $10 \% \mathrm{I}-\mathrm{HS}$, displays a much better mechanical behavior with a long rubbery plateau.

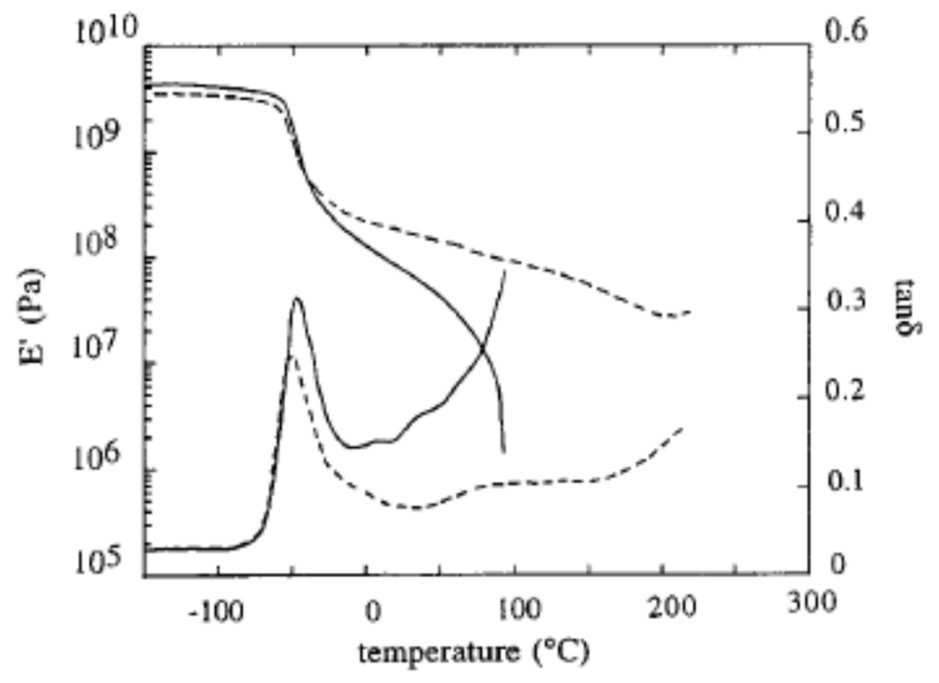

Figure 10 Storage modulus $E^{\prime}$ and loss factor tan $\delta$ curves for segmented polyureas based on D-2000, $\mathrm{H}_{12} \mathrm{MDI}$, and aromatic diamines ( $39 \mathrm{wt} \%$ hard segment): (- -) Ethacure 300; (- - -) MDEA.

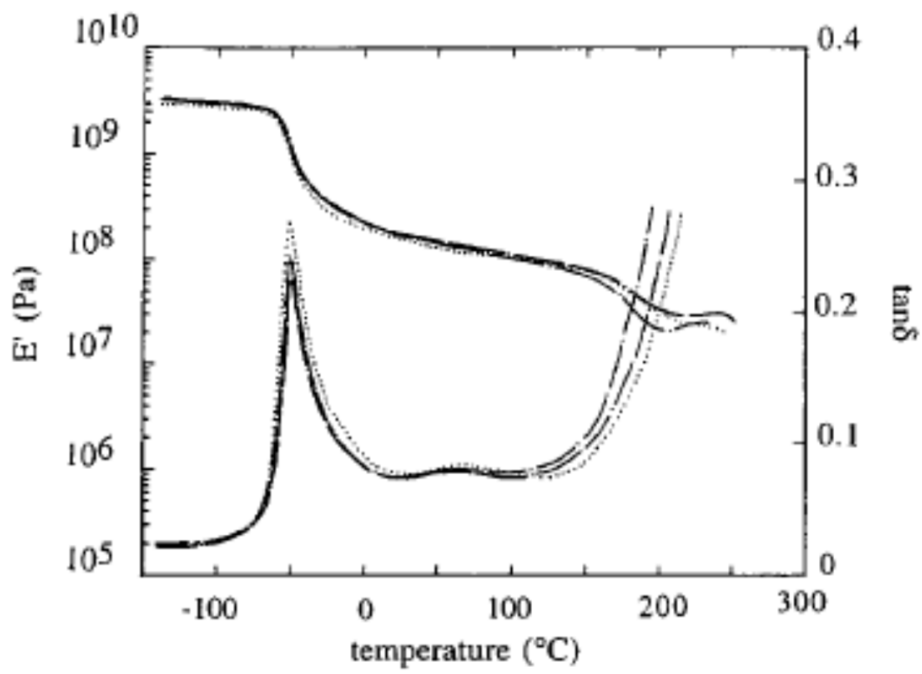

Figure 11 Storage modulus $E^{\prime}$ and loss factor tan $\delta$ curves for segmented polyureas based on D-2000, $\mathrm{H}_{12} \mathrm{MDI}$, and cycloaliphatic diamines ( $39 \mathrm{wt} \%$ hard segment): (. . .) PACM; (. - .) 3-DCM; (- - .) M-MECHA. 
Concerning the segmented polyureas based on cycloaliphatic chain extenders, the intensity of the low temperature $\tan \delta$ peak, $\alpha_{s}$, is in the following order: M-MECHA $<3-\mathrm{DCM}<\mathrm{PACM}$. This reflects a greater phase segregation in the case of PACM and is consistent with its higher crystallinity deduced from the value of the hard segment melting enthalpy $\left(\Delta H_{m}, \mathrm{~J} / \mathrm{g}\right.$ hard segment, see Table IV). Although the three diamines have very similar structures (Table I), the rubbery modulus seems to increase slightly with the steric hindrance of the diamine, maybe because at the same time the volume fraction of "fillers" increases as well; but the rubbery plateau is still slightly longer with PACM, in agreement with a higher $\overline{M_{n}}$.

For all the materials except that derived from Ethacure 300, a shoulder in the $\tan \delta$ curves can be observed between 50 and $100^{\circ} \mathrm{C}$. Ryan et al. ${ }^{4}$ observed the same phenomenon for segmented polyurethane ureas obtained by RIM. According to these authors, it could be ascribed to cooperative molecular relaxations of mixed soft and hard segments linked by intersegmental hydrogen bonds between urea groups and ethers from the Jeffamine chain; but in our case, it is more certainly due to the presence of low molar masses that induce a high energy dissipation.

At high temperature (except Ethacure 300 ) a relaxation accompanied by a drop in $E^{\prime}$ is observed and can be associated with the glass transition of the hard domains. Whatever the chain extender, $T_{\alpha}{ }^{h}$ is equal to $160^{\circ} \mathrm{C}$.

\section{Effect of Thermal Treatment at $200^{\circ} \mathrm{C}$}

Figure 12 describes the typical effects of a thermal treatment performed at $200^{\circ} \mathrm{C}$ during $90 \mathrm{~min}$ on the plates formerly molded at $150^{\circ} \mathrm{C}$ for $30 \mathrm{~min}$. The same observations can be made with every chain extender, except that no result could be obtained with the Ethacure 300 based sample because degradation occurred at $200^{\circ} \mathrm{C}$, leading to a very brittle material. The corresponding data are summed up in Table VI.

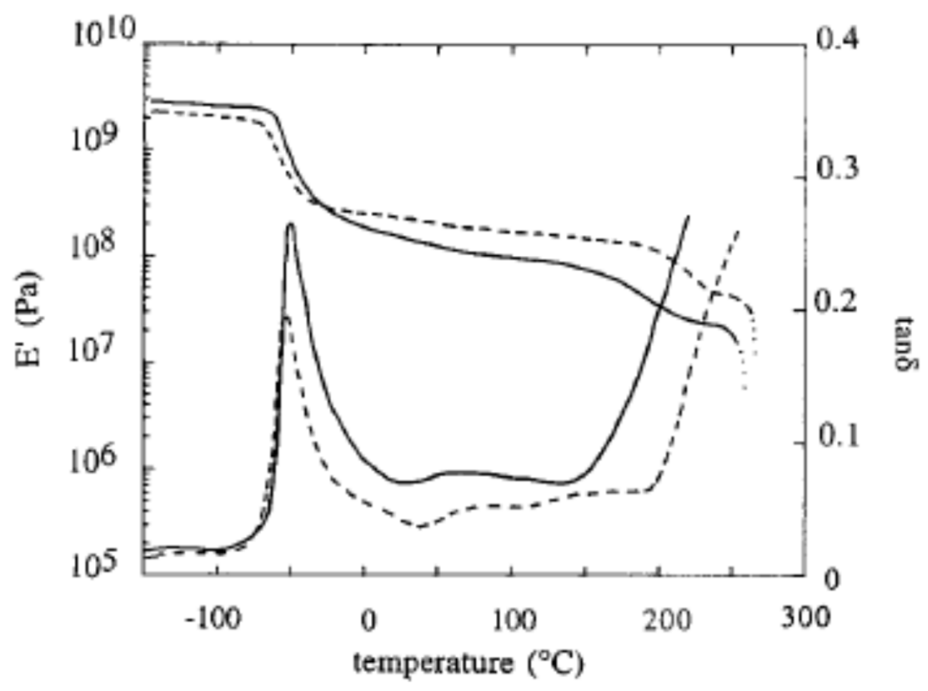

Figure 12 Effect of a postcuring at $200^{\circ} \mathrm{C}$ on the storage modulus and loss factor of a D2000/ $\mathrm{H}_{12} \mathrm{MDI} / \mathrm{PACM}(1 / 3 / 2)$ segmented polyurea: (--) non-postcured; (- - -) postcured $90 \mathrm{~min}$ at $200^{\circ} \mathrm{C}$. 
Table VI Dynamic mechanical properties of segmented polyureas based on D-2000, $\mathrm{H}_{12} \mathrm{MDI}$, and various chain extenders (1/3/2)

\begin{tabular}{|c|c|c|c|c|c|c|c|c|c|c|}
\hline \multirow{2}{*}{ Chain extender } & \multicolumn{6}{|c|}{ Non-postcured } & \multicolumn{4}{|c|}{ Post-cured $\left(90 \mathrm{~min}\right.$ at $\left.200^{\circ} \mathrm{C}\right)$} \\
\hline & $\begin{array}{c}T_{\alpha}^{s} \\
\left({ }^{\circ} \mathrm{C}\right)^{\mathrm{a}}\end{array}$ & $\begin{array}{c}E_{c}^{\prime}\left(20^{\circ} \mathrm{C}\right) \\
(\mathrm{MPa})\end{array}$ & $\frac{E^{\prime}\left(20^{\circ} C\right)}{E^{\prime}\left(80^{\circ} C\right)}$ & $\begin{array}{c}T_{\alpha}^{h} \\
\left({ }^{\circ} \mathrm{C}\right)^{\mathrm{a}}\end{array}$ & $\begin{array}{c}\tan \delta \text { peak } \\
\text { height }\end{array}$ & $\begin{array}{c}\tan \delta \text { peak height } \\
\text { (100\% soft segment) }\end{array}$ & $\begin{array}{c}T_{\alpha}^{s} \\
\left({ }^{\circ} \mathrm{C}\right)^{\mathrm{a}}\end{array}$ & $\begin{array}{c}E_{c}^{\prime}\left(20^{\circ} \mathrm{C}\right) \\
(\mathrm{MPa})\end{array}$ & $\frac{E^{\prime}\left(20^{\circ} \boldsymbol{C}\right)}{E^{\prime}\left(80^{\circ} \boldsymbol{C}\right)}$ & $\begin{array}{c}T_{\alpha}^{h} \\
\left({ }^{\circ} \mathrm{C}\right)^{\mathrm{a}}\end{array}$ \\
\hline Ethacure 300 & -63 & 79 & 3.3 & 60 & 0.31 & 0.50 & b/ & b/ & b/ & b/ \\
\hline MDEA & -64 & 171 & 1.6 & 160 & 0.25 & 0.43 & -65 & 186 & 1.5 & 190 \\
\hline PACM & -63 & 154 & 1.5 & 160 & 0.27 & 0.43 & -65 & 223 & 1.2 & 180 \\
\hline 3-DCM & -63 & 174 & 1.6 & 160 & 0.24 & 0.39 & -65 & 155 & 1.3 & 180 \\
\hline M-MECHA & -63 & 181 & 1.5 & 160 & 0.23 & 0.39 & -65 & 227 & 1.3 & 180 \\
\hline
\end{tabular}

a Onset temperature for the drop of $E^{\prime}$.

${ }^{\mathrm{b}}$ Sample based on Ethacure 300 degraded on posturing. 
Several structural changes are induced by aging at $200^{\circ} \mathrm{C}$. For every polyurea, the $T_{\alpha}^{s} \tan \delta$ peak is shifted to lower temperature and the onset of the drop in $E^{\prime}$ shifted from -63 to $-65^{\circ} \mathrm{C}$. There is also a decrease in the height of the $\alpha_{s}$ peak, as well as in the shoulder between $\alpha_{s}$ and $\alpha_{h}$ ( $\tan \delta$ decreases from $\sim 0.08$ to $\sim 0.05$ ). Finally, the rubbery modulus is generally higher (except with 3-DCM) after postcuring, and the rubbery plateau is longer; the second drop in $E^{\prime}$, ascribed to the hard domain glass transition, is shifted from 160 to $180-190^{\circ} \mathrm{C}$. All this suggests that materials postcured only at $150^{\circ} \mathrm{C}$ were incompletely reacted and thus contained $\mathrm{NH}_{2}$ or $\mathrm{NCO}$ terminated chains that can only move and react on postcuring above a certain temperature, presumably the former $T_{\alpha}{ }^{h}$ because of a kind of vitrification phenomenon. Another explanation could be the occurrence of intermolecular rearrangements and transuretization reactions. It was indeed impossible to remeasure molar masses after postcuring because the materials were no longer completely soluble, even after TFA modification. A thermal treatment at $200^{\circ} \mathrm{C}$ can thus be supposed to induce two types of reaction: chain extension and crosslinking (through biuret linkages or transuretization). In other words, postcuring at $200^{\circ} \mathrm{C}$ increases the modulus by forcing the reaction to completion and creating some intermolecular linkages, and reduces damping by improving the level of microphase separation. ${ }^{6}$ Table VI suggests that it probably leads only to a better phase separation for 3-DCM.

The postcured segmented polyurea D-2000/ $\mathrm{H}_{12} \mathrm{MDI} / \mathrm{M}-\mathrm{MECHA}$ [4,4'-methylene-bis(2-methyl 6-ethyl cyclohexylamine] can be compared with the corresponding D-2000/ $\mathrm{H}_{12} \mathrm{MDI} / \mathrm{MDECA}$ obtained by RIM at $85^{\circ} \mathrm{C}$ by Ryan et al. ${ }^{3}$ [MDECA $=4,4^{\prime}$-methylene-bis(2,6-diethyl cyclohexylamine)]. In the latter case, $T_{g} \mathrm{~S}$ was measured as the maximum of the low temperature $\tan \delta$ peak at $-53^{\circ} \mathrm{C}$ (versus $-51^{\circ} \mathrm{C}$ for our samples). Moreover, storage moduli are quite comparable: at $20^{\circ} \mathrm{C}$ Ryan et al. ${ }^{3}$ found $G^{\prime} \approx 200 \mathrm{MPa}$ for D-2000/ $\mathrm{H}_{12} \mathrm{MDI} / \mathrm{MDECA}$ (50 wt \% hard segment) whereas we obtained $E^{\prime}=615 \mathrm{MPa}$ for D-2000/ $\mathrm{H}_{12} \mathrm{MDI} / \mathrm{M}-\mathrm{MECHA}$ (54 wt \% hard segment), with $E \approx 3 G$ for elastomers. $T_{g}{ }^{h}$ values are also very close, because both can be measured as the drop in $E^{\prime}$ at high temperature around $180^{\circ} \mathrm{C}$. Finally between $\alpha_{s}$ and $\alpha_{h}$, the polyurea based on MDECA also displays a low but continuous energy dissipation ( $\tan \delta \approx 0.05$ ). Therefore, the dynamic mechanical properties obtained with segmented polyureas prepared by catalyzed solution polycondensation with postcuring at $200^{\circ} \mathrm{C}$ are in total agreement with those of similar materials obtained by a bulk (RIM) procedure with a mold temperature of $85^{\circ} \mathrm{C}$.

$T_{\alpha}{ }^{h}$ represents the upper limit temperature for the use of such materials. Our samples compare favorably with other closely related materials: for polyurethane ureas based on polyoxypropylene $\left(\overline{M_{n}}=2000\right), \mathrm{MDI}$, and ethylene diamine, Takahara et al. ${ }^{19}$ found $180^{\circ} \mathrm{C}$; for RIM-synthesized polyureas derived from Jeffamine D-2000, MDI, and DETDA, Ryan ${ }^{2}$ obtained $230^{\circ} \mathrm{C}$, that is, higher than our values but with a much more rigid hard segment (MDI instead of $\mathrm{H}_{12} \mathrm{MDI}$ ). Classical polyurethanes do not show such high values $\left(T_{\alpha}{ }^{h} \approx 130^{\circ} \mathrm{C}\right.$ for polyurethanes based on MDI and 1,4-butanediol, $150^{\circ} \mathrm{C}$ for polyurethanes based on MDI and hydroquinone bis( $\beta$-hydroxyethyl) ether). Recently, longer rubbery plateaux were obtained with polyurethanes based on MDI and 1,4:3,6 dianhydro-D-sorbitol. ${ }^{39}$ However, urea groups are still assumed to have a better thermal resistance than urethane groups. In short, these new segmented polyureas (except D-2000/ $\mathrm{H}_{12} \mathrm{MDI} /$ Ethacure 300 ), which exhibit high values of $T_{\alpha}{ }^{h}$ and a stable rubbery plateau up to $T_{\alpha}{ }^{h}$, can be good candidates when elastomers with satisfactory thermal stability up to $160-180^{\circ} \mathrm{C}$ are required. The only problem could be the high energy dissipation induced by the high value of $G^{\prime \prime}$ (or $\tan \delta$ ) at room temperature. 


\section{Tensile Properties}

The results of tensile stress-strain studies performed on non-postcured samples are presented in Table VII in the form of Young's modulus, $E$, ultimate stress (or tensile strength), $\sigma_{u}$, and ultimate strain (or elongation at break), $\varepsilon_{u}$.

Table VII Molar masses and tensile properties of segmented polyureas based on D-2000, $\mathrm{H}_{12} \mathrm{MDI}$, and various chain extenders (stoichiometry $1 / 3 / 2$ )

\begin{tabular}{|l|c|c|c|c|c|}
\hline \multicolumn{1}{|c|}{ Chain extender } & $\begin{array}{c}\overline{\boldsymbol{M}_{\boldsymbol{n}}} \\
\mathbf{( g / \text { mol) }}\end{array}$ & I-HS (\%) & $\boldsymbol{E}$ (MPa) & $\sigma_{u}$ (MPa) & $\mathcal{E}_{u}$ (\%) \\
\hline${\text { Ethacure } 300^{\mathrm{b}}}_{\text {MDEA }^{\mathrm{c}}}$ & 7600 & 36 & $5 \pm 1$ & $15 \pm 1$ & $283 \pm 20$ \\
PACM $^{\mathrm{b}}$ & 8300 & 10 & $118 \pm 30$ & $34 \pm 1$ & $271 \pm 20$ \\
3-DCM $^{\mathrm{b}}$ & 34200 & 0 & $106 \pm 5$ & $22 \pm 1$ & $257 \pm 30$ \\
M-MECHA $^{\mathrm{b}}$ & 25500 & 0 & $86 \pm 20$ & $21 \pm 1$ & $320 \pm 30$ \\
\hline
\end{tabular}

${ }^{a}$ Relative area of the isolated hard-segment (I-HS) peak in SEC chromatograms.

${ }^{\mathrm{b}}$ After a $100 \%$ strain, no residual strain.

${ }^{c}$ After a $100 \%$ strain, $20 \%$ residual strain.

In agreement with its poor molar masses, molar mass distribution, and dynamic mechanical properties, $E$ and $\sigma_{u}$ values obtained with the D-2000/ $\mathrm{H}_{12} \mathrm{MDI} /$ Ethacure 300 segmented polyurea are much lower than those obtained for all other materials. However, the value of $\mathcal{E}_{u}(283 \pm 20 \%)$ is still acceptable. This mechanical behavior reveals that there is no filler effect due to the hard domains in this case, as already concluded from the dynamic analysis (Fig. 10).

Concerning the other polyureas, $E, \sigma_{u}$, and $\varepsilon_{u}$ values are homogeneous: $\mathrm{E} \approx 100 \mathrm{MPa}, \sigma_{u} \approx 25 \mathrm{MPa}$, and $\varepsilon_{u} \approx 250 \%$. All the values of $E$ (Young) are lower than $E^{\prime}$ (storage) (see Table VI) but remain in the same range. However, for the sample prepared from MDEA, a $100 \%$ strain is sufficient to induce a $20 \%$ residual strain; in this respect this material is not a real elastomer. This could perhaps be related to the high $G^{\prime \prime}$ or $\tan \delta$ value at room temperature and can probably be explained by the low molar mass and non-negligible amount of isolated hard segment ( $10 \%$ as estimated by SEC), although this effect is not observed for the Ethacure 300 based material that has even poorer characteristics.

The polyureas based on cycloaliphatic diamines do not show any residual strain after a $100 \%$ strain and behave like real elastomers.

\section{CONCLUSION}

A series of new segmented polyureas and their corresponding pure hard segments based on a polyoxypropylene soft chain and diisocyanate-4,4'-dicyclohexylmethane were synthesized by bulk or solution polycondensation. The reacting systems were tested for their processability, and the resulting materials were tested for their molar masses and molar mass distributions and thermal properties. Molar mass distributions are a direct consequence of the competition between polycondensation 
kinetics and hard segment crystallization. Pure hard segments indeed show a high crystallinity degree; in the case of segmented polyureas, early crystallization leads to the formation of I-HSs and stops the reaction by creating a two-phase system with unbalanced stoichiometry, which finally results in very low molar masses. However, the use of more reactive components and a catalyst enhances the reaction kinetics sufficiently to compete with the hard segment crystallization rate and to obtain narrower molar mass distributions and higher molar masses. Consequently, our final aim to determine specific formulations, which could be suitable for processing by simple casting with a bulk procedure, turned out to be difficult to achieve, because a sufficient lowering of reactivity seems to be accompanied by an almost ineluctable early crystallization inducing low molar masses. But the segmented polyureas prepared from cycloaliphatic diamines by a solution procedure nevertheless display interesting thermal characteristics.

The dynamic mechanical properties and tensile properties were then studied as a function of chain extender nature and hard segment content. As expected from the above physicochemical characterization, the best results were obtained for the materials derived from cycloaliphatic chain extenders using a catalyzed solution procedure. Aromatic compounds led to poor mechanical behaviors at high (MDEA) or even low (Ethacure 300) strain levels, presumably because their low reactivity induced early hard segment crystallization and prevented the creation of chemical linkages between hard and soft phases. On the contrary, cycloaliphatic chain extenders led to elastomers that can be used up to $180-190^{\circ} \mathrm{C}$ while retaining good mechanical properties; postcuring at sufficiently high temperature $\left(200^{\circ} \mathrm{C}\right)$ can improve these properties by completing the reaction (to maximum chain extension) and increasing phase separation. A perfect control of the competition between chemistry and phase transitions is thus essential to obtain materials with the desired final properties.

Financial support from the Société d'Applications de Moulages Industriels (SAMI), as well as helpful discussions, are gratefully acknowledged.

\section{REFERENCES}

1. W. R. Willkomm, Z. S. Chen, C. W. Macosko, D. A. Gobran, and E. L. Thomas, Polym. Eng. Sci., 28, 288 (1988).

2. A. J. Ryan, Polymer, 31, 707 (1990).

3. A. J. Ryan, T. B. Bergstrom, W. R. Willkomm, and C. W. Macosko, J. Appl. Polym. Sci., 42, 1023 (1991).

4. A. J. Ryan, J. L. Stanford, and R. H. Still, Polymer, 32, 1426 (1991).

5. Y. Gao, Y. Y. Xiu, Z. Q. Pan, D. N. Wang, C. P. Hu, and S. K. Ying, J. Appl. Polym. Sci., 53, 23 (1994).

6. A. J. Ryan, J. L. Stanford, and X. Q. Tao, Polymer, 34, 4020 (1993).

7. C. Z. Yang, C. Li, and S. L. Cooper, J. Polym. Sci. Polym. Phys., B29, 75 (1991).

8. A. R. Ray and A. Bhowmick, J. Macromol. Sci. Chem., A28, 1009 (1991).

9. Y. Xiu, D. Wang, C. P. Hu, S. K. Ying, and J. Li, J. Appl. Polym. Sci., 48, 867 (1993).

10. T. O. Ahn, L. L. S. Choi, H. M. Jeong, and K. Choi, Polym. Int., 31, 329 (1993).

11. H. K. Lee and S. W. Ko, J. Appl. Polym. Sci., 50, 1269 (1993). 
12. D. Joel, W. Hettrich, and R. Becker, Polymer, 34, 2623 (1993).

13. D. Joel, G. Pohl, and W. G. Hiller, Angew. Makromol. Chem., 208, 107 (1993).

14. Z. S. Chen, W. P. Yang, and C. W. Macosko, Rubber Chem. Technol., 61, 86 (1988).

15. A. J. Ryan, J. L. Stanford, and A. N. Wilkinson, Polym. Bull., 18, 517 (1987).

16. A. J. Birch, J. L. Stanford, and A. J. Ryan, Polym. Bull., 22, 629 (1989).

17. J. L. Stanford, A. N. Wilkinson, D. K. Lee, and A. J. Ryan, Plast. Rubb. Process. Applic., 13, 111 (1990).

18. A. J. Ryan, J. L. Stanford, and A. J. Birch, Polymer, 34, 4874 (1993).

19. A. Takahara, J. L. Tashita, T. Kajiyama, M. Takayanagi, and W. J. McKnight, Polymer, 26, 987 (1985).

20. J. L. Stanford, R. H. Still, and A. N. Wilkinson, Polymer, 36, 3555 (1995).

21. C. S. Park Sung, T. W. Smith, and N. H. Sung, Macromolecules, 13, 117 (1980).

22. C. B. Wang and S. L. Cooper, Macromolecules, 16, 775 (1983).

23. J. H. Saunders and K. C. Frisch, High Polymers-Polyurethanes Chemistry and Technology, Vol. XVI, Part I, Interscience Publishers, Wiley, New York, 1962, p. 65.

24. E. Jacobi, H. Schuttenberg, and R. C. Schultz, Makromol. Chem. Rapid Commun., 1, 397 (1980).

25. E. Biagini, E. Gattiglia, E. Pedemonte, and S. Russo, Makromol. Chem., 184, 1213 (1983).

26. V. Darud, Ph.D. dissertation, INSA Lyon, 1988.

27. L. Cuvé, J. P. Pascault, G. Boiteux, and G. Seytre, Polymer, 32, 343 (1991).

28. R. Bonart, L. Morbitzer, and E. H. Müller, J. Macromol. Sci. Phys., B9, 447 (1974).

29. S. Yoshikawa and D. J. Lyman, J. Polym. Sci. Polym. Lett. Ed., 18, 411 (1980).

30. Y. Camberlin and J. P. Pascault, J. Polym. Sci. Polym. Chem. Ed., 20, 383 (1982).

31. M. C. Pannone and C. W. Macosko, J. Appl. Polym. Sci., 34, 2409 (1987).

32. J. H. Saunders and K. C. Frisch, High Polymers-Polyurethanes Chemistry and Technology, Vol. XVI, Part I, Interscience Publishers, Wiley, New York, 1962, p. 179.

33. J. Robbins, J. Appl. Polym. Sci., 9, 821 (1965).

34. T. E. Lipatova, L. A. Bakalo, Yu. N. Niselski, and A. L. Sirotinskaya, J. Macromol. Sci. Chem., A4, 1743 (1970).

35. L. Thiele and R. Becker, Adv. Urethane Sci. Technol., 12, 59 (1993).

36. P. Kolodziej, C. W. Macosko, and W. E. Ranz, Polym. Eng. Sci., 22, 388 (1982).

37. R. E. Camargo, C. W.Macosko, M. V. Tirrell, and S. T. Wellinghoff, Polym. Eng. Sci., 22, 719 (1982).

38. R. E. Camargo, C. W.Macosko, M. Tirrell, and S. T. Wellinghoff, Polymer, 26, 1145 (1985).

39. E. Cognet-Georjon, F. Méchin, and J. P. Pascault, Macromol. Chem. Phys., 197, 3593 (1996). 